\title{
Distinct Physiological Maturation of Parvalbumin-Positive Neuron Subtypes in Mouse Prefrontal Cortex
}

\author{
Takeaki Miyamae, ${ }^{1}$ Kehui Chen, ${ }^{2}$ DDavid A. Lewis, ${ }^{1}$ and ${ }^{\circledR}$ Guillermo Gonzalez-Burgos ${ }^{1}$ \\ ${ }^{1}$ Translational Neuroscience Program, Department of Psychiatry, and ${ }^{2}$ Department of Statistics, University of Pittsburgh, Pittsburgh, Pennsylvania 15261
}

Parvalbumin-positive $\left(\mathrm{PV}^{+}\right)$neurons control the timing of pyramidal cell output in cortical neuron networks. In the prefrontal cortex (PFC), $\mathrm{PV}^{+}$neuron activity is involved in cognitive function, suggesting that $\mathrm{PV}^{+}$neuron maturation is critical for cognitive development. The two major $\mathrm{PV}^{+}$neuron subtypes found in the PFC, chandelier cells (ChCs) and basket cells (BCs), are thought to play different roles in cortical circuits, but the trajectories of their physiological maturation have not been compared. Using two separate mouse lines, we found that in the mature PFC, both ChCs and BCs are abundant in superficial layer 2, but only BCs are present in deeper laminar locations. This distinctive laminar distribution was observed by postnatal day 12 (P12), when we first identified ChCs by the presence of axon cartridges. Electrophysiology analysis of excitatory synapse development, starting at P12, showed that excitatory drive remains low throughout development in ChCs, but increases rapidly before puberty in BCs, with an earlier time course in deeper-layer BCs. Consistent with a role of excitatory synaptic drive in the maturation of $\mathrm{PV}^{+}$neuron firing properties, the fast-spiking phenotype showed different maturation trajectories between $\mathrm{ChCs}$ and $\mathrm{BCs}$, and between superficial versus deep-layer BCs. ChC and BC maturation was nearly completed, via different trajectories, before the onset of puberty. These findings suggest that $\mathrm{ChC}$ and $\mathrm{BC}$ maturation may contribute differentially to the emergence of cognitive function, primarily during prepubertal development.

Key words: action potential; basket neuron; chandelier neuron; parvalbumin; prefrontal cortex; synaptic current

Significance Statement

Parvalbumin-positive $\left(\mathrm{PV}^{+}\right)$neurons tightly control pyramidal cell output. Thus $\mathrm{PV}^{+}$neuron maturation in the prefrontal cortex (PFC) is crucial for cognitive development. However, the relative physiological maturation of the two major subtypes of $\mathrm{PV}^{+}$ neurons, chandelier cells (ChCs) and basket cells (BCs), has not been determined. We assessed the maturation of ChCs and BCs in different layers of the mouse PFC, and found that, from early postnatal age, ChCs and BCs differ in laminar location. Excitatory synapses and fast-spiking properties matured before the onset of puberty in both cell types, but following cell type-specific developmental trajectories. Hence, the physiological maturation of ChCs and BCs may contribute to the emergence of cognitive function differentially, and predominantly during prepubertal development.

\section{Introduction}

Parvalbumin-positive $\left(\mathrm{PV}^{+}\right)$neurons tightly control the timing of pyramidal cell output in cortical neuron networks (Sohal et al., 2009; Roux and Buzsáki, 2015). Consistent with this essential role, $\mathrm{PV}^{+}$neuron activity in the prefrontal cortex (PFC) is di-

\footnotetext{
Received Oct. 26, 2016; revised March 6, 2017; accepted April 6, 2017.

Author contributions: T.M., D.A.L., and G.G.-B. designed research; T.M. and G.G.-B. performed research; T.M., K.C., and G.G.-B. analyzed data; T.M., K.C., D.A.L., and G.G.-B. wrote the paper.

This work was supported by National Institutes of Health Grants MH51234 and P50MH103204. We thank Olga Krimer for her excellent technical assistance with histological techniques and reconstructions of neuron morphology. We thank Dr. Tatiana Tikhonova for providing some of the biocytin-filled neurons.

D.A.L. currently receives investigator-initiated research support from Pfizer.

Correspondence should be addressed to Guillermo Gonzalez-Burgos, Translational Neuroscience Program, Department of Psychiatry, University of Pittsburgh School of Medicine, Room W1651 Biomedical Science Tower, 200 Lothrop Street, Pittsburgh, PA 15261. E-mail: gburgos@pitt.edu.

DOI:10.1523/JNEUROSCI.3325-16.2017

Copyright $\odot 2017$ the authors $\quad 0270-6474 / 17 / 374883-20 \$ 15.00 / 0$
}

rectly involved in cognitive function (Cho et al., 2015; Kim et al., 2016; Lagler et al., 2016), and $\mathrm{PV}^{+}$neuron alterations in the PFC contribute to the disturbances of oscillatory network synchrony thought to underlie cognitive deficits in schizophrenia (GonzalezBurgos et al., 2015). Given their importance for PFC function, the postnatal maturation of $\mathrm{PV}^{+}$neurons could contribute significantly to the emergence of PFC-dependent cognitive abilities that improve substantially during childhood and adolescence (Luna et al., 2015), and are impaired in schizophrenia. Thus, investigating the postnatal maturation of $\mathrm{PV}^{+}$neurons in the PFC is crucial to elucidate their role in cognitive development.

The two major subtypes of cortical $\mathrm{PV}^{+}$neurons, basket cells (BCs) and chandelier cells (ChCs), are distinguished by morphological features of their axons, which target separate compartments of the postsynaptic cell membrane. Specifically, ChC axons display abundant vertical arrays of synaptic boutons, termed cartridges, which innervate the initial segment of the pyramidal neu- 
ron axon (DeFelipe et al., 2013). In contrast, BC axons lack cartridges, and target the pyramidal cell body and proximal dendrites (DeFelipe et al., 2013). Interestingly, ChCs may be excitatory, instead of inhibitory, depending on the network activity state (Szabadics et al., 2006; Woodruff et al., 2009, 2011). Moreover, in vivo, ChCs fire spikes with different timing than BCs (Zhu et al., 2004; Klausberger and Somogyi, 2008; Massi et al., 2012). These notable differences, and the proximity of ChC synapses to the site of action potential (AP) initiation (Kole and Stuart, 2012), suggest that $\mathrm{ChCs}$ and $\mathrm{BCs}$ play different roles in cortical circuit function. Therefore, $\mathrm{ChC}$ and $\mathrm{BC}$ maturation may contribute differently to the development of PFC circuits and cognitive function. To date, however, the time course of physiological maturation of ChCs and BCs has not been compared in any cortical region.

Previous studies suggested that the unique fast-spiking (FS) electrophysiological phenotype of $\mathrm{PV}^{+}$neurons, which is essential for their role in cortical networks (Buzsáki and Wang, 2012; Hu et al., 2014), develops in an activity-dependent manner (Miller et al., 2011; Dehorter et al., 2015). Therefore, excitatory drive from glutamate synapses may shape the maturation the FS phenotype, and thus excitatory synapses and FS properties may display similar maturation time courses. In addition, although in adult cortex $\mathrm{PV}^{+}$neurons are present in layers 2-6 (Gabbott et al., 1997; Chattopadhyaya et al., 2004; Rymar and Sadikot, 2007; Bartolini et al., 2013), $\mathrm{PV}^{+}$cells populate the deep layers first during early development (Rymar and Sadikot, 2007; Bartolini et al., 2013). Thus, the maturation time course of $\mathrm{PV}^{+}$neurons may differ between layers.

To test these ideas, we investigated the functional maturation of excitatory synapses and of FS properties in ChCs and BCs across cortical layers in the PFC. We found, in two independent mouse strains, that BCs are positioned throughout layers 2-5, whereas $\mathrm{ChC}$ somata are found only near the layer 1-2 (L1/2) border. Developmental analysis of $\mathrm{PV}^{+}$neurons from postnatal day $(\mathrm{P}) 12$ revealed that excitatory synaptic drive did not change with age in $\mathrm{L} 1 / 2 \mathrm{ChCs}$, but increased rapidly in BCs, reaching levels $\sim 4$ times higher than in L1/2 ChCs, and possibly with an earlier onset in BCs of layers 3-5 (L3/5) compared with L1/2 BCs. Consistent with a role of excitatory synaptic drive in the maturation of the FS phenotype, FS properties developed with the slowest rate in L1/2 ChCs, and possibly with earlier onset in L3/5 BCs than in L1/2 BCs. Importantly, independent of subtypedependent and layer-dependent differences, the maturation of all $\mathrm{PV}^{+}$neurons in mouse PFC was rapid and almost completed by the onset of puberty. Thus, $\mathrm{PV}^{+}$neuron maturation may contribute to the emergence of cognitive function primarily during prepubertal development.

\section{Materials and Methods}

\section{Brain-slice preparation}

Coronal brain slices (300 $\mu \mathrm{m}$ thick) containing various subregions of the medial PFC (medial orbital, infralimbic, prelimbic, and dorsal anterior cingulate) were prepared from the frontal cortex of mice of either sex, ranging in age from P8 to P73. Animal housing and all procedures followed National Institutes of Health guidelines, approved by the University of Pittsburgh Institutional Animal Care and Use Committee. Under deep isoflurane anesthesia, the mice were decapitated. Then a tissue block was dissected and glued to the stage of a vibrating microtome (Leica Microsystems, VT1000). Slices were cut in ice-cold slicing solution containing the following (in mM): 210 sucrose, $10 \mathrm{NaCl}, 1.9 \mathrm{KCl}, 1.2$ $\mathrm{Na}_{2} \mathrm{HPO}_{4}, 33 \mathrm{NaHCO}_{3}, 20$ glucose, 1.3 ascorbate, 2.4 pyruvate, $6 \mathrm{MgCl}_{2}$, $0.5 \mathrm{CaCl}_{2}$, pH 7.3-7.4 when bubbled with $95 \% \mathrm{O}_{2}$ and $5 \% \mathrm{CO}_{2}$. Before recording, slices were incubated at room temperature $\left(20-24^{\circ} \mathrm{C}\right)$ for $\geq 60$ min in a holding chamber filled with artificial CSF (ACSF) containing the following (in mM): $125 \mathrm{NaCl}, 2.5 \mathrm{KCl}, 1.25 \mathrm{Na}_{2} \mathrm{HPO}_{4}, 10$ glucose, 25
$\mathrm{NaHCO}_{3}, 0.4$ ascorbate, $1 \mathrm{MgCl}_{2}, 2 \mathrm{CaCl}_{2}, \mathrm{pH} 7.3-7.4$ when gassed with 95\% $\mathrm{O}_{2}$ and $5 \% \mathrm{CO}_{2}$. In most experiments, slices were from $\mathrm{G} 42$ mice (The Jackson Laboratory, stock no. 007677), a transgenic line expressing green fluorescence protein (GFP) exclusively in $\mathrm{PV}^{+}$neurons (Chattopadhyaya et al., 2004). In some experiments, we used mice expressing cre recombinase (Cre) and the red fluorescent protein tdTomato in $\mathrm{PV}^{+}$ neurons, derived from crossing Pvalb ${ }^{C r e}$ mice, a knock-in strain expressing Cre in $\mathrm{PV}^{+}$neurons (The Jackson Laboratory, stock no. 008069), with mice of the tdTomato reporter knock-in line Ail4 (The Jackson Laboratory, stock no. 007908). Because tdTomato expression is very low in immature $\mathrm{PV}^{+}$neurons labeled in Pvalb ${ }^{\text {Cre }}$ mice (Carlén et al., 2012), the $P$ valb ${ }^{C r e}$;Ailu line was used only to study $\mathrm{PV}^{+}$neurons at age $\mathrm{P} \geq 30$.

\section{Electrophysiological recording and data analysis}

For recording, the slices were transferred to a submersion chamber superfused at $2 \mathrm{ml} / \mathrm{min}$ with oxygenated ACSF solution at $30-32^{\circ} \mathrm{C}$, containing $10 \mu \mathrm{M}$ gabazine, a $\mathrm{GABA}_{\mathrm{A}}$ receptor antagonist, to block inhibitory synaptic currents. Tight-seal whole-cell recordings were obtained from $\mathrm{PV}^{+}$neurons identified by the GFP or tdTomato fluorescence, using Olympus or Zeiss microscopes equipped with epifluorescence, infrared illumination, differential interference contrast, and CCD video cameras (EXi Aqua, Q-Imaging). Pipettes pulled from borosilicate glass (resistance, 3-6 M $\Omega$ ) were filled with the following solution (mM): 120 potassium gluconate, $10 \mathrm{KCl}, 10 \mathrm{HEPES}, 0.2 \mathrm{EGTA}, 4.5 \mathrm{MgATP}, 0.3$ NaGTP, 14 sodium phosphocreatine. The $\mathrm{pH}$ was adjusted to 7.2-7.4 using $\mathrm{KOH}$. Biocytin $(0.4-0.5 \%)$ was freshly added to the pipette solution to fill the $\mathrm{PV}^{+}$cells for later morphological identification. Recordings were obtained with Multiclamp 700B amplifiers (Molecular Devices). Signals were low-pass filtered at $6 \mathrm{kHz}$, and digitized at 10 or $20 \mathrm{kHz}$ using Power 1401 data acquisition interfaces (Cambridge Electronic Design). Data acquisition and analysis were performed using Signal 5 software (Cambridge Electronic Design), running custom-made scripts.

Voltage-clamp experiments. We compensated the pipette capacitance $\left(C_{\mathrm{p}}\right)$ and continuously monitored the series resistance $(R s)$, but did not use $R s$ compensation. $R s$ was estimated as $R s=5 / I(0)$, where $I(0)$ is the initial amplitude of the capacitive current evoked by a $5 \mathrm{mV}$ voltage step, excluding the current due to charging of $C_{\mathrm{p}}$. To estimate $I(0)$ minimizing errors from variability in the accuracy of $C_{\mathrm{p}}$ compensation, we use a script written in Signal software that fits, to the capacitive current, a double exponential function as follows (Eq. 1):

$$
I(t)=A+B * \exp \left(-\frac{t}{\tau_{B}}\right)+C * \exp \left(-\frac{t}{\tau_{c}}\right)
$$

To exclude the current due to charging of $C_{\mathrm{p}}$, the first millisecond of current was omitted from the fits (Langdon et al., 1995). At $t=0, I(0)=$ $A+B+C$, thus Rs $(\mathrm{M} \Omega)=5(\mathrm{mV}) / A+B+C(\mathrm{nA})$. Only recordings with an initial $R s<20 \mathrm{M} \Omega$ were used for analysis. The $R s$ values (mean \pm $\mathrm{SD})$ were $10.3 \pm 3.5 \mathrm{M} \Omega(n=60), 10.6 \pm 3.3 \mathrm{M} \Omega(n=37)$, and $10.5 \pm$ $2.7 \mathrm{M} \Omega(n=43)$ for recordings from $\mathrm{L} 1 / 2 \mathrm{BCs}, \mathrm{L} 1 / 2 \mathrm{ChCs}$, and L3/5 BCs, respectively.

EPSCs were recorded holding the $\mathrm{PV}^{+}$neurons at $-70 \mathrm{mV}$, near their average resting membrane potential, which ranged between -60.8 and $-79.7 \mathrm{mV}$ (see Figs. 8, 9, 11, 12). The stability of Rs was measured by the current evoked by a $50 \mathrm{~ms}-5 \mathrm{mV}$ voltage step, delivered every $10 \mathrm{~s}$. EPSC data analysis was completed in a short time window with small changes in $R s$, which increased on average by $1.3,4.1$, and $1.4 \%$, in $\mathrm{L} 1 / 2 \mathrm{BC}, \mathrm{L} 1 / 2$ $\mathrm{ChC}$, and $\mathrm{L} 3 / 5 \mathrm{BC}$ recordings, respectively. Importantly, the initial $R s$ (mean $\pm \mathrm{SD}$ ) did not differ with age in the recordings from L1/2 BCs (P12: $10.9 \pm 4.9 \mathrm{M} \Omega$; P20: $9.9 \pm 3.2 \mathrm{M} \Omega$; P30-P40: $11.6 \pm 1.3 \mathrm{M} \Omega$; $\left.F_{(2,17)}=0.199, p=0.821\right), \mathrm{L} 1 / 2 \mathrm{ChCs}(\mathrm{P} 12: 10.9 \pm 4.6 \mathrm{M} \Omega$; P20: $9.7 \pm$ $2.1 \mathrm{M} \Omega$; P30-P40: $\left.10.7 \pm 2.5 \mathrm{M} \Omega ; F_{(2,17)}=0.136, p=0.874\right)$, or L3/5 BCs (P12: $10.4 \pm 3.6 \mathrm{M} \Omega$; P20: $10.6 \pm 1.7 \mathrm{M} \Omega$; P30-P40: $9.8 \pm 3.2 \mathrm{M} \Omega$; $\left.F_{(2,23)}=0.142, p=0.867\right)$. Therefore, age-related differences in sEPSC properties were unlikely to reflect different voltage-clamp quality due to differences in Rs.

For each recorded $\mathrm{PV}^{+}$neuron, 100-200 sEPSCs were detected and analyzed using Mini Analysis software (Synaptosoft), starting $\sim 1 \mathrm{~min}$ after the beginning of whole-cell recordings. For EPSC detection, the 
amplitude threshold was 4-6 pA (two times the root mean square of the baseline noise, typically 2-3 pA). The EPSC area threshold was $4 \mathrm{pA} / \mathrm{ms}$; the average baseline before EPSC onset was set as 2-10 ms. The sEPSCs detected were inspected visually, and all detected events were used to estimate the mean peak sEPSC amplitude and sEPSC frequency. The mean sEPSC amplitude reported for each neuron is the average of the amplitudes measured for each sEPSC detected for each cell. The sEPSC frequency reported is the mean number of sEPSCs detected per second, thus expressed in hertz.

EPSC trains (see Fig. 4) were evoked using electrodes pulled from borosilicate theta capillary glass, filled with oxygenated extracellular solution and connected to a stimulation unit via silver wires. Pulses of 100 $\mu$ s duration had amplitudes $(10-100 \mu \mathrm{A})$ that in each neuron evoked EPSCs reliably (see Fig. 4A). When testing the effect of tetrodotoxin (TTX) on sEPSCs (see Fig. 4), we monitored the block of APs produced by voltage escape during large depolarizing commands (sometimes termed action currents).

Current-clamp experiments. Only cells with an initial resting membrane potential of -60 to $-80 \mathrm{mV}$ were included in this study. $R s$ and $C_{\mathrm{p}}$ were monitored and cancelled using the bridge balance and capacitance neutralization circuits. The input resistance $\left(R_{\text {in }}\right)$ was estimated as the slope of the linear region of the relation between hyperpolarizing current step amplitude ( -50 to $-10 \mathrm{pA}, 500 \mathrm{~ms}$, three repeats) injected via the recording electrode, and membrane potential during the last $50 \mathrm{~ms}$ of the step. The membrane time constant $\left(\tau_{\mathrm{m}}\right)$ was estimated fitting a single exponential function to the decay of the membrane potential response produced by hyperpolarizing steps of -30 to $-10 \mathrm{pA}$ (three repeats per step). This measure is an approximation of the actual $\tau_{\mathrm{m}}$, which, in a passive neuron with complex geometry, is the time constant of the slowest component of a multiexponential time course (Spruston et al., 1994). The voltage threshold to fire an AP (AP threshold), AP duration at half maximal amplitude (AP half-width), afterhyperpolarization (AHP) amplitude, and delay to fire the first AP (first AP delay), were all estimated from single APs ( $\geq 3$ replicates per neuron), evoked by stimulation at or near the current threshold (I threshold). The AP threshold was estimated using derivatives of $V_{\mathrm{m}}(t)$, as described previously (Henze et al., 2000). The AHP amplitude was estimated as the difference between the AP threshold and the voltage at the AHP trough. I threshold was the smallest current step amplitude eliciting $\geq 1 \mathrm{AP}$ in three repetitions of that step amplitude. The slope of the relation between mean firing frequency and current step amplitude ( $f-I$ slope) was estimated from the linear region of the plots of mean firing frequency versus stimulus amplitude. The mean firing frequency was calculated from the number of APs evoked per $500 \mathrm{~ms}$ stimulus, averaged for the three repetitions of each stimulus amplitude. Spike frequency adaptation was estimated as the ratio between the last and first interspike interval (ISI): ISI ratio, ISI $_{(\text {last })} / \mathrm{ISI}_{\text {(first) }}$. For stimulus currents between $I$ threshold and $\sim 100 \mathrm{pA}$ above, $\mathrm{PV}^{+}$ neurons fired single (see Fig. $6 A$ ) or a few APs with highly variable ISIs (data not shown). Between 100 and 200 pA above $I$ threshold, the ISI ratio was stable for BCs, but increased progressively in ChCs. The ISI ratio values reported are the average from steps between 100 and $200 \mathrm{pA}$ above $I$ threshold. For several neurons reported in Figures 8, 10, 11, and 13 , current-clamp recordings were obtained after voltage-clamp data were acquired, which are reported in Figures 3 and 5.

\section{Histological processing and morphological reconstruction of biocytin-filled neurons}

The $\mathrm{PV}^{+}$neurons were filled with $0.4-0.5 \%$ biocytin during recordings, and then slices were immersed in $4 \% \mathrm{p}$-formaldehyde in $0.1 \mathrm{M}$ PBS for $24-72 \mathrm{~h}$ at $4^{\circ} \mathrm{C}$. The slices were cryoprotected (33\% glycerol, 33\% ethylene glycol, in $0.1 \mathrm{M}$ PBS) and stored at $-80^{\circ} \mathrm{C}$ until processed. To visualize biocytin, the slices were resectioned at $60 \mu \mathrm{m}$, incubated with $1 \%$ $\mathrm{H}_{2} \mathrm{O}_{2}$, and immersed in blocking serum containing $0.5 \%$ Triton X-100 for $2-3 \mathrm{~h}$ at room temperature. The tissue was then rinsed and incubated with the avidin-biotin-peroxidase complex (1:100; Vector Laboratories) in PBS for $4 \mathrm{~h}$ at room temperature. Sections were rinsed, stained with the nickel-enhanced 3,3' -diaminobenzidine chromogen, mounted on gelatin-coated glass slides, dehydrated, and coverslipped. Three- dimensional reconstructions were performed using the Neurolucida tracing system (MBF Bioscience).

ChCs are morphologically defined by an axonal arbor with abundant cartridges, which are short rows of boutons aligned vertically and connected by thin axonal segments (Somogyi et al., 1998; DeFelipe et al., 2013). In the PFC of mice $P \geq 28$, ChCs could be identified both by the presence of cartridges, and their overall axo-dendritic features, as described in previous studies (Woodruff et al., 2011; Inan et al., 2013). ChC axons in mouse somatosensory cortex display adult-like properties since P18, by frequently displaying four (range, 2-9) boutons per cartridge (Inan et al., 2013). With differential interference contrast imaging of the biocytin-filled axonal arbors, we could identify cartridges with $\geq 4$ axonal boutons only in $\mathrm{PV}^{+}$neurons from $\mathrm{P} \geq 12$ mice. In many cases, the biocytin-labeled boutons in cartridges were in apposition with the unlabeled axon initial segment of pyramidal neurons. However, $\mathrm{PV}^{+}$cells from the P8-P11 PFC lacked axon cartridges, although many of them displayed axo-dendritic features consistent with those of ChCs. Thus, we identified a neuron as $\mathrm{ChC}$ when $\geq 2-3$ cartridges (with $\geq 4$ boutons per cartridge) were detected in the axonal arbor, and the global axo-dendritic features were consistent with mature ChCs. Using this criteria, ChCs could be identified starting at P12. Because many cartridges in mature ChC axons have $<4$ boutons (Inan et al., 2013), our approach may have excluded some immature ChCs.

Figure $1 E$ reports the distance between center of the soma and pial surface, measured, using the Neurolucida software, over a line nearly perpendicular to the pial surface and the L1/2 border, for $109 \mathrm{GFP}^{+}$ neurons ( $66 \mathrm{BCs}, 43 \mathrm{ChCs}$ ) from $\mathrm{P} \geq 28$ mice. These include cells with electrophysiology data displayed in Figures 3, 4, 5, 8, and 9, and GFP ${ }^{+}$ neurons filled with biocytin during recordings for which the electrophysiology data quality did not meet criteria for inclusion in analysis. For many of the ChCs and BCs with electrophysiology data in this study, the soma-to-pia distance was not measured, but microscope inspection showed that all ChC somata were localized exclusively near the L1/2 border, whereas $B C s$ were found throughout all layers. Figure $1 F$ reports data from biocytinfilled neurons from Pvalb ${ }^{\text {Cre }}$;Ail4 mice. For some of these mice we report electrophysiological data in this study (see Figs. 9, 11).

\section{Statistical analysis}

Basic statistics. In the figures, the data were expressed as means \pm SD, unless otherwise indicated. To determine whether postnatal age and neuron subtype had significant effects on the electrophysiological properties (excitatory synaptic function and FS phenotype), we employed Student's $t$ tests or ANOVA. To assess normality of the data distribution, we constructed quantile-quantile (Q-Q) plots of the residuals for each variable, followed by Shapiro-Wilk tests of normality. Some variables were natural log transformed to meet the criteria of normality assumption, as indicated in each figure legend. In the figures, these variables are shown without transformation.

Exponential curve fitting and comparisons. To characterize the time course of maturation of the electrophysiological properties, we employed nonlinear curve fitting of single exponential functions of the following form (Eq. 2): $y(x)=y_{0}+A * \exp \left(-\frac{x-12}{\tau_{d e v}}\right)$, where $y$ is the physiological variable, and $x$ is mouse age in days. The parameter $y 0$ (plateau value), represents the mature state, and $A$ sets the value, relative to $y 0$, at age $\mathrm{P} 12$, thus indicating the amount of change between $\mathrm{P} 12$ and mature state (for some variables, $A$ is a negative number). The exponential constant $\tau_{\mathrm{dev}}$ defines the rate of maturation, and is the time needed for $y$ to decay by $0.63^{\star} A$. We chose a single exponential decay as the model function given that, for the variables more strongly regulated by age (for example, AP half-width, $R_{\mathrm{in}}$, and $\tau_{\mathrm{m}}$ ), a single exponential decay function fit the data better than a linear regression or a logistic function, as judged by the coefficient of determination $R^{2}$, and a double exponential decay did not substantially improve the fits. Interestingly, a previous study of $\mathrm{PV}^{+} \mathrm{BCs}$ (Doischer et al., 2008) showed that the development of several of the electrophysiological variables studied here was also well fit by single exponential functions.

We compared the maturation time course between L1/2 BCs and L1/2 ChCs, or between L1/2 BCs and L3/5 BCs, using a combined exponential curve-fitting approach applied to the electrophysiological variables that, 

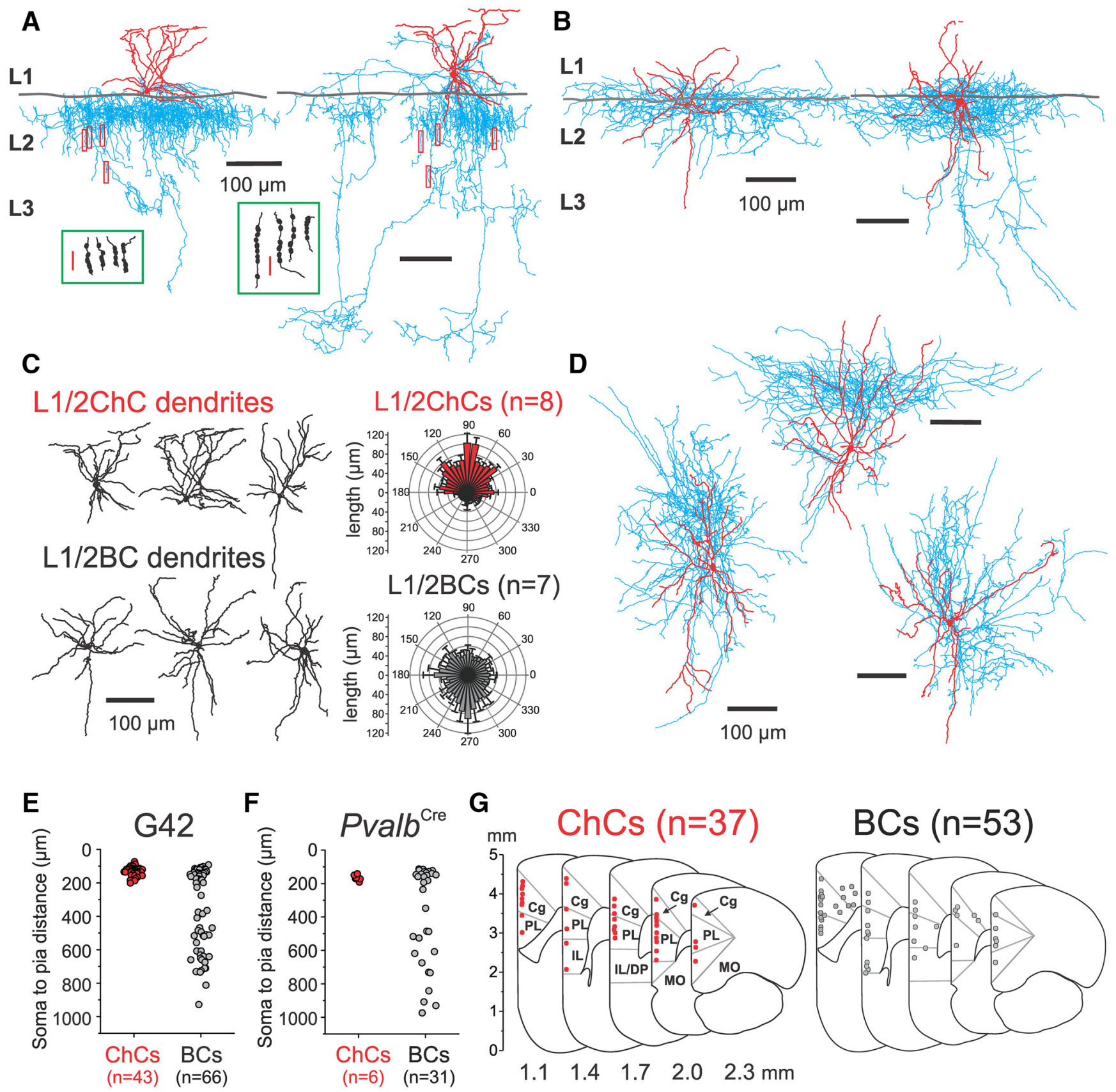

Figure 1. Morphological features of $\mathrm{PV}^{+}$neurons in the PFC of $\mathrm{P} \geq 28 \mathrm{G} 42$ mice. $A$, Neurolucida reconstructions of two examples of ChCs (left, P63; right, P28), filled with biocytin during recordings near the L1/2 border. The axon is shown in blue; soma and dendrites are in red. Note the presence of abundant cartridges of axonal boutons, some of which (red boxes) are highlighted in the insets (green boxes). Here, and in $\boldsymbol{B}$, the gray lines illustrate the approximate location of the L1/2 border. As noted in the examples, many of the ChCs had prominent axonal projections descending into deeper cortical layers. Calibration bars for the insets, $10 \mu \mathrm{m}$. B, Neurolucida reconstructions of two examples of $\mathrm{L} 1 / 2 \mathrm{BCs}$ (left, P62; right, P28). $\boldsymbol{C}$, Neurolucida reconstructions of the somata and dendritic tree for examples of $\mathrm{L} 1 / 2 \mathrm{ChCs}$ and $\mathrm{L} 1 / 2 \mathrm{BCS}$. Right, Polar plots of the distribution of dendritic length relative to the soma, positioned at the center, averaged for two samples of $\mathrm{L} 1 / 2 \mathrm{ChCS}(n=8)$ and $\mathrm{L} 1 / 2 \mathrm{BCS}(n=7)$. Shown are means \pm SEM. $\boldsymbol{D}$, Neurolucida reconstructions of examples of $\mathrm{L} 3 / 5 \mathrm{BCS} \boldsymbol{E}$, Plots of distance between the center of the soma and the pial surface for $\mathrm{PV}^{+}$neurons recorded from the PFC of G42 mice. F, Plots of distance between the center of the soma and pial surface for $\mathrm{PV}^{+}{ }^{+}$neurons recorded in the PFC of Pvalb ${ }^{\text {Cre }}$;Ai14 mice. G, Approximate localization of the cell bodies, across subregions of the mouse frontal cortex, of a subset of the $\mathrm{PV}^{+} \mathrm{ChCs}$ and BCs reported in $E$. PV ${ }^{+}$neurons from G42 or Pvalb ${ }^{\text {Cre }}$; Ai14 mice not shown in $\mathbf{G}$ were found in the same cytoarchitectonic regions. Red and gray dots represent, respectively, somata of individual ChCs and BCs. The numbers below the schematics, show the anterior-posterior (A-P) coordinates of the coronal sections. These coordinates are approximate, since the A-P location of the most rostral section varied between experiments. C $\mathrm{g}$, Anterior cingulate; PL, prelimbic; MO, medial orbital; IL/DP, infralimbic/dorsal peduncular. Abbreviations of cytoarchitectonic regions as defined in the 2001 atlas of Paxinos and Franklin (2001).

by $t$ test, showed effect of age within each subtype under consideration. For the $\mathrm{L} 1 / 2 \mathrm{ChC}$ versus $\mathrm{L} 1 / 2 \mathrm{BC}$ comparison, the variables were as follows: $R_{\mathrm{in}}$ : L1/2 ChC $p=0.006, \mathrm{~L} 1 / 2 \mathrm{BC} p=0.0001$; AP half-width: L1/2 ChC $p<0.00001, \mathrm{~L} 1 / 2 \mathrm{BC} p<0.00001$; AP threshold: $\mathrm{L} 1 / 2 \mathrm{ChC} p=$ $0.013, \mathrm{~L} 1 / 2 \mathrm{BC} p=0.029 ; \tau_{\mathrm{m}}: \mathrm{L} 1 / 2 \mathrm{ChC} p=0.00028, \mathrm{~L} 1 / 2 \mathrm{BC} p<$ 0.00001 ; $f-I$ slope: $\mathrm{L} 1 / 2 \mathrm{ChC} p=0.011, \mathrm{~L} 1 / 2 \mathrm{BC} p=0.00022$. For the $\mathrm{L} 1 / 2 \mathrm{BC}$ versus $\mathrm{L} 3 / 5 \mathrm{BC}$ comparison, the variables were as follows: $\mathrm{AP}$ half-width: $\mathrm{L} 3 / 5 \mathrm{BCs} p=0.000024 ; \tau_{\mathrm{m}}$ : L3/5 BCs $p<0.00001$; I threshold: L1/2 BCs $p=0.000013, \mathrm{~L} 3 / 5 \mathrm{BCs} p=0.00058 ; R_{\mathrm{in}}$ : L3/5 BCs $p=$ $0.00002 ; f-I$ slope: $\mathrm{L} 3 / 5$ BCs $p=0.00039$. The combined exponential curve-fit approach was also employed to compare the maturation rate of sEPSC frequency between L1/2 BCs and L3/5 BCs.

Using R 3.1.0 software (The R Project for Statistical Computing, https://www.r-project.org/), we applied exponential curve fits to the data 


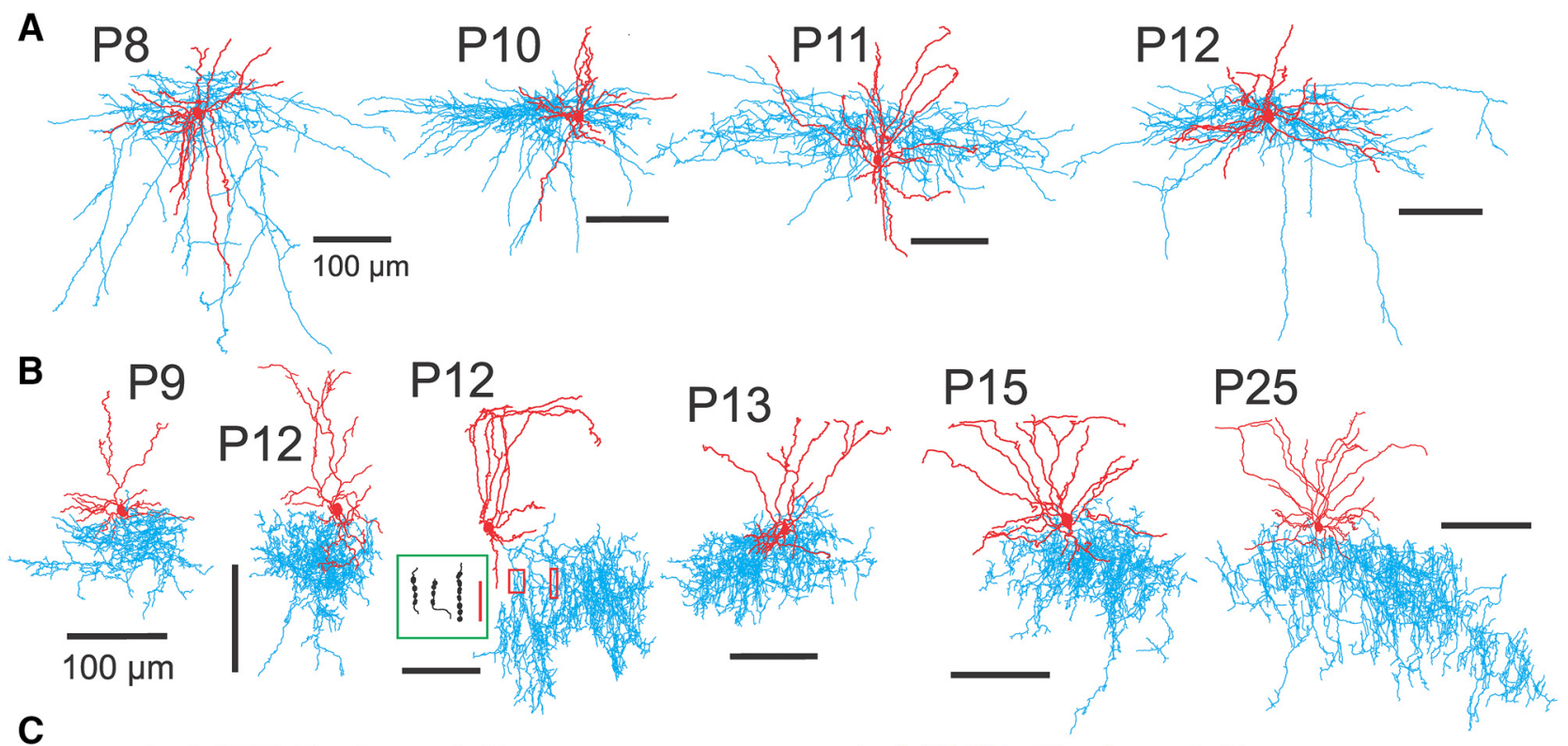

C

\section{L1/2BC dendrites}

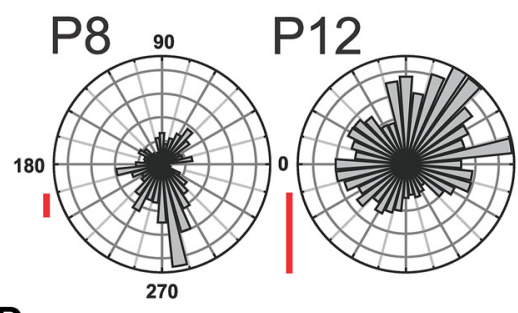

D

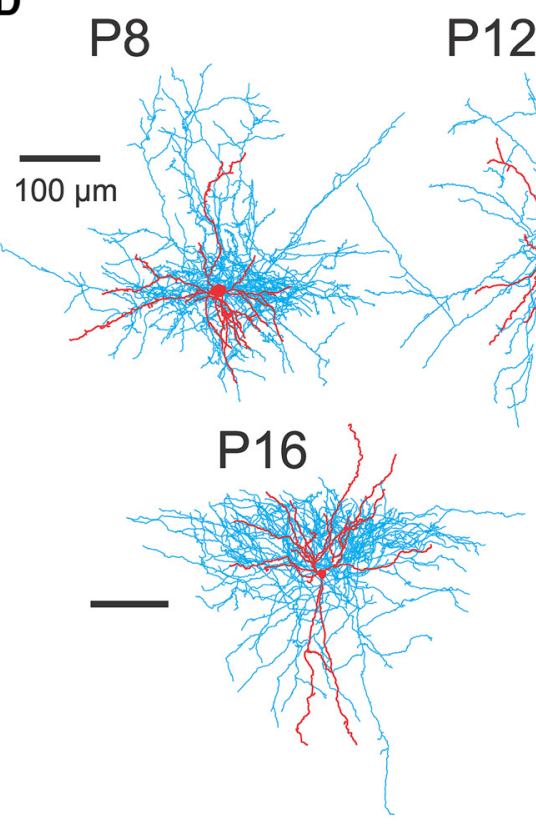

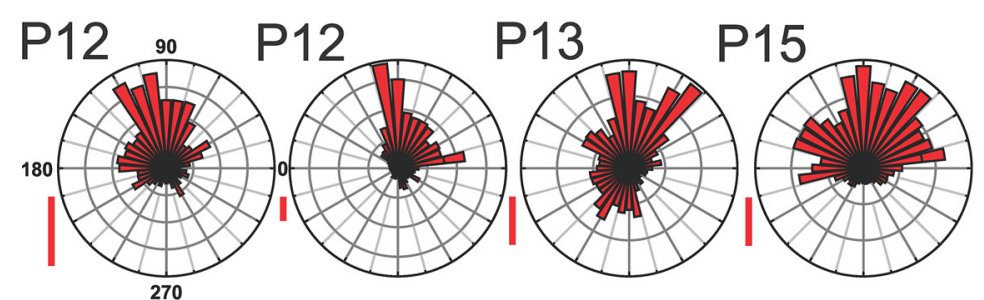

E

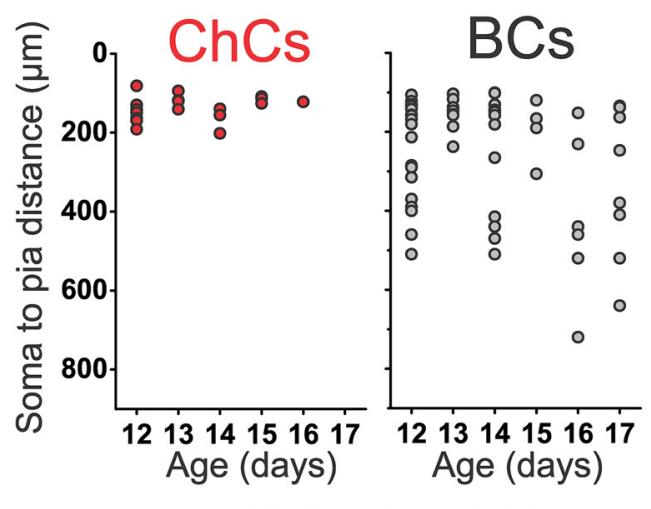

$\mathbf{F}$

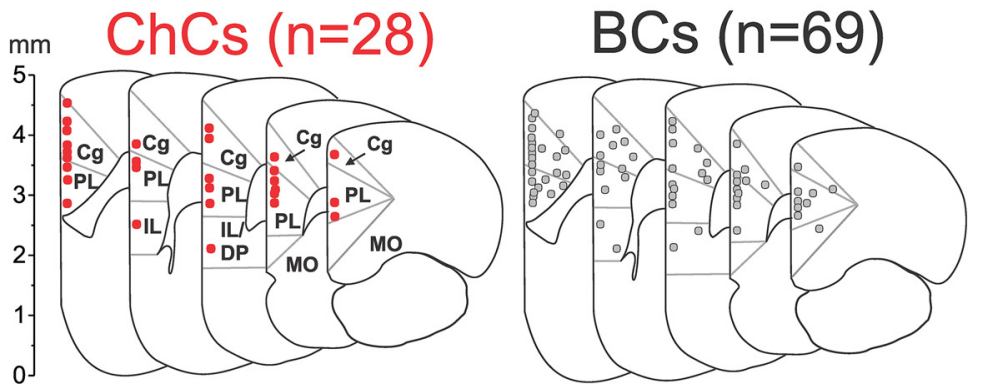

$\begin{array}{lllll}1.1 & 1.4 & 1.7 & 2.0 & 2.3 \\ \mathbf{m m}\end{array}$

Figure 2. Morphological properties of $\mathrm{PV}{ }^{+}$neurons in the developing mouse PFC. $A$, Neurolucida reconstructions of examples of $\mathrm{L} 1 / 2 \mathrm{BC} S$ from $\mathrm{P} 8$-P12 $\mathrm{G} 42$ mice. The axon is shown in blue; soma and dendrites are shown in red. $B$, Neurolucida reconstructions of examples of L1/2 ChCs from P9-P25 G42 mice. Note the presence of cartridges of axonal boutons in a P12 L1/2 ChC, highlighted in the insets (green boxes). Calibration bars for the insets, $10 \mu \mathrm{m}$. C, Individual polar plots of the distribution of dendritic length relative to the soma, positioned at the center, for two L1/2 BCs (P8 and P12) and four L1/2 ChCs (P12-P15). Calibration bars, $40 \mu \mathrm{m}$. D, Neurolucida reconstructions of examples of L3/5 BCs in P8 -P16 G42 mice. E, Plots of distance between the center of the soma and the pial surface for $\mathrm{PV}{ }^{+}$neurons recorded in the PFC of P12-P17 G42 mice. F, Distribution of the recorded PV ${ }^{+}$ChCs and BCs across subregions of the medial PFC of P $\leq 20 \mathrm{G} 42$ mice. Cg, Anterior cingulate; PL, prelimbic; MO, medial orbital; IL/DP, infralimbic/dorsal peduncular. Red and gray dots represent, respectively, somata of individual ChCs and BCs. The calibration and anteriorposterior coordinates of the coronal section schematics are approximate, given that the brains of mice younger than P14 have slightly smaller dimensions, and that the anterior-posterior location of the most rostral section varied between experiments. 
A CNQX

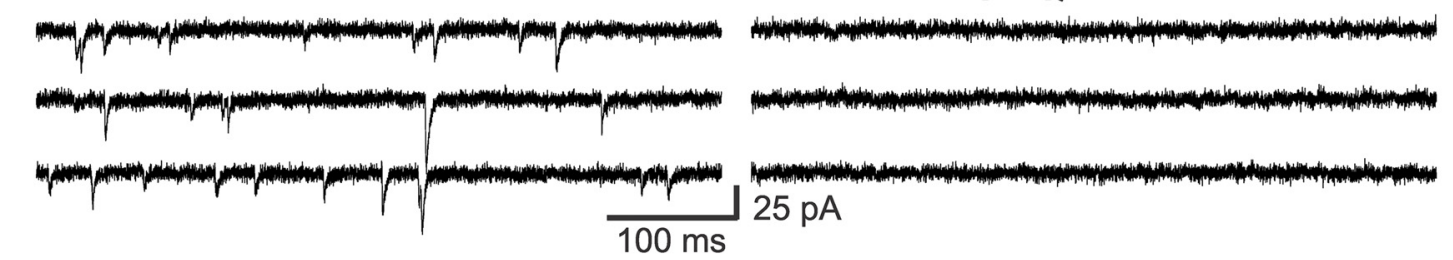

B

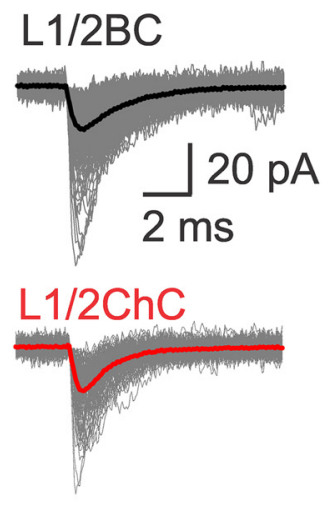

E

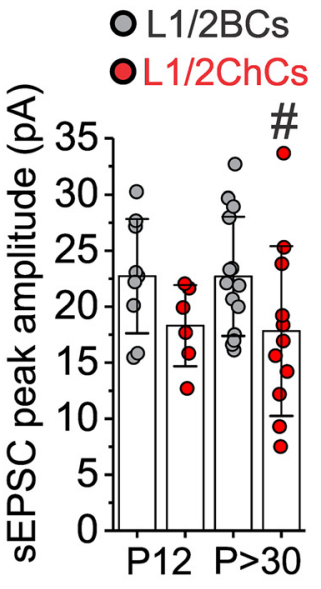

G

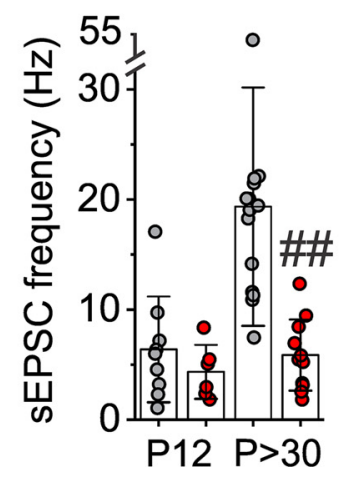

C

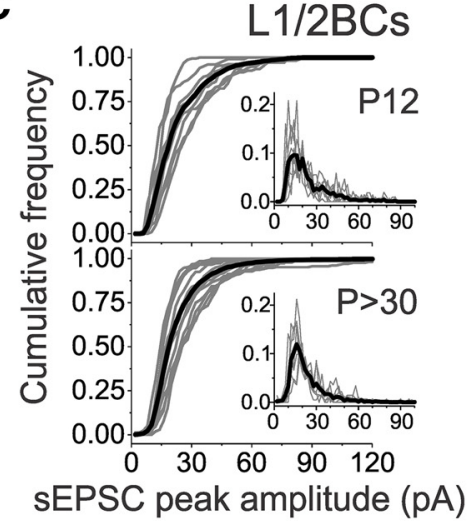

D

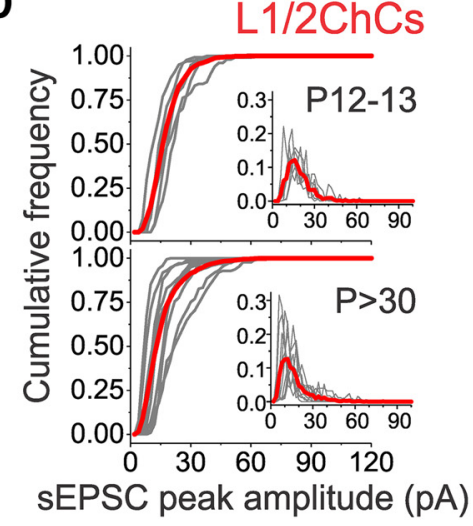

F

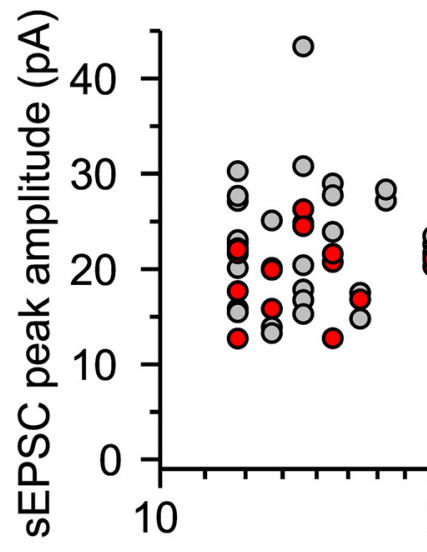

H

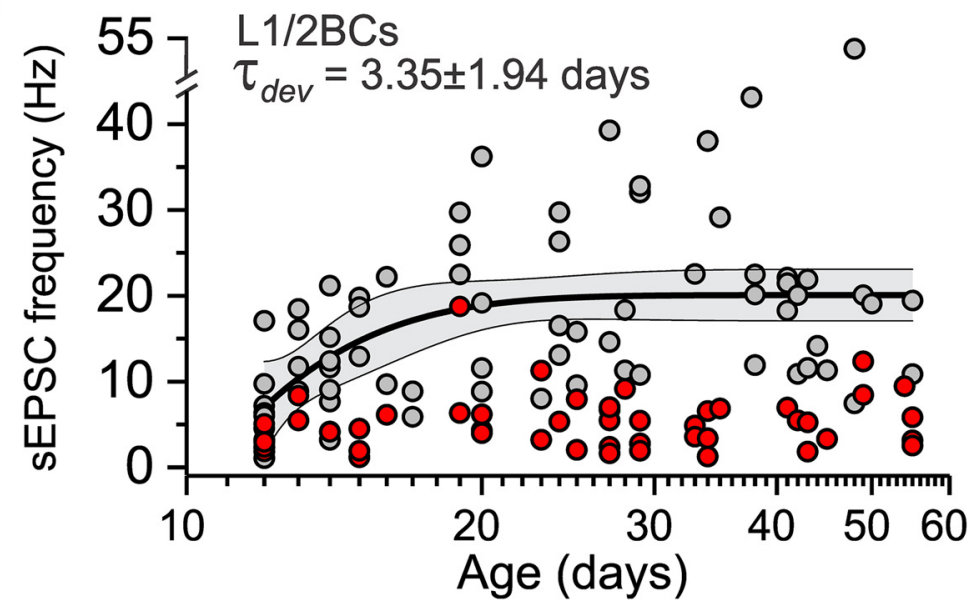

Figure 3. Developmental changes of EPSCS in PV ${ }^{+}$neurons of the $L 1 / 2$ border in mouse PFC. $A$, Left, Representative examples of sEPSCs recorded from a $L 1 / 2 B C$ in the continuous presence of

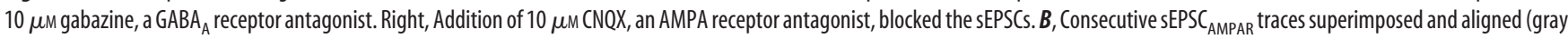
traces, 130 sEPSCs), together with their average, for a P12 L1/2 BC (black thick trace) and a P12 L1/2 ChC (red thick trace). C, Cumulative frequency distribution of sEPSC ${ }_{\text {AMPAR }}$ amplitude for P12 ( $n=$ 9 ) and P35-P50 ( $n=14) \mathrm{L} 1 / 2 \mathrm{BC}$. Here and in $\boldsymbol{D}$, the insets show binned histograms of the relative frequency ( $y$-axis) of $\mathrm{SEPSC}_{\mathrm{AMPAR}}$ amplitude $(x$-axis) for each sample. $\boldsymbol{D}$, Cumulative frequency

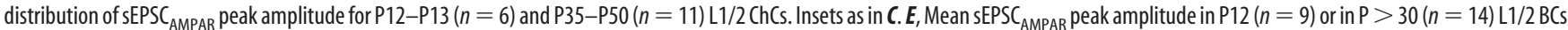
(gray symbols), and in P12-P13 $(n=6)$ or P $>30(n=11) \mathrm{L} 1 / 2 \mathrm{ChC}$ (red symbols). Two-factor ANOVAs revealed lack of effect of age $\left(F_{(1,36)}=0.0103, p=0.899\right)$ and significant effect of cell type $\left(F_{(1,36)}=6.159, p=0.0212\right)$. At $\mathrm{P}>30$, the sEPSC $C_{\text {AMPAR }}$ amplitude was significantly smaller in $\mathrm{L} 1 / 2$ ChCs (\#p $=0.044$, Fisher's least significant difference test). $F$, Plot of mean sEPSC $C_{\text {AMPAR }}$ peak amplitude as a function of postnatal age for L1/2 BCs (gray symbols) or L1/2 ChCs (red symbols). Each data point represents a single PV ${ }^{+}$neuron. $G$, Mean (Figure legend continues.) 
from each neuron subtype. For all the variables indicated above, we obtained a curve fit (see Fig. 10,13), with the exception of $R_{\text {in }}$ in L1/2 ChCs, for which the fitting algorithm did not converge, despite testing many combinations of initial values for the fit parameters (we programmed a loop to search over a dense grid with 50 values for each parameter), indicating that there is no unique solution for the curve fit. Overall, either the absence of age effect or the lack of fit in the data plots for one or both of the $\mathrm{PV}^{+}$neuron subtypes under consideration precluded comparing some variables. The variables for which we compared the exponential fits were, between L1/2 BCs and L1/2 ChCs: AP halfwidth, $\tau_{\mathrm{m}}$, AP threshold, and $f-I$ slope, and between L1/2 BCs and L3/5 BCs: AP half-width, $\tau_{\mathrm{m}}, I$ threshold, $R_{\mathrm{in}}$, and $f-I$ slope.

To contrast the rate of development between $\mathrm{PV}^{+}$neuron samples, we combined the data points for a given electrophysiological variable from the two samples under consideration, creating a dummy variable $z, 0$ for $\mathrm{L} 1 / 2 \mathrm{BCs}$, and 1 for L1/2 ChCs (or L3/5 BCs). The general model fitted had two predictors $\left(x\right.$ and $z$ ) and six parameters $\left(y 0, y 0^{\prime}, A, A^{\prime}, \tau_{\mathrm{dev}}\right.$, and $\tau_{\mathrm{dev}}^{\prime}$ ) as follows (Eq. 3):

$$
y(x)=\left(y 0+y 0^{\prime} * z\right)+\left(A+A^{\prime} * z\right) * \exp \left(-\frac{x-12}{\tau_{d e v}+\tau_{d e v}^{\prime} * z}\right),
$$

where non-zero values of $y 0^{\prime}, A^{\prime}, \tau_{\mathrm{dev}}^{\prime}$ indicate these parameters are different between the two samples under comparison. Whereas $y 0, y 0^{\prime}, A$, and $A^{\prime}$ may be estimated from the experimental data (via the $\mathrm{P}>30$ and P12 values, respectively), the rate of development can only be estimated via $\tau_{\mathrm{dev}}$ from the curve fits. Thus, our approach focused on comparing $\tau_{\mathrm{dev}}$ (i.e., testing whether $\tau_{\mathrm{dev}}^{\prime}>0$ ). To this aim, whenever there was no evidence of difference in $\mathrm{P}>30$ and $\mathrm{P} 12$ values, $y 0^{\prime}$ and $A^{\prime}$ were omitted, and the model thus had two predictors $(x$ and $z$ ) and four parameters $\left(y 0, A, \tau_{\mathrm{dev}}\right.$, and $\tau_{\mathrm{dev}}^{\prime}$ ). This allowed us to focus the comparisons on $\tau_{\mathrm{dev}}$, because the statistical power is greater when the number of parameters in the model is reduced. For the comparison between L1/2 BCs and L1/2 ChCs, both $y 0^{\prime}$ and $A^{\prime}$ were omitted in the combined curve fit, except that for $\tau_{\mathrm{m}}$ (see Fig. 8), we kept $y 0^{\prime}$. For the comparison between L1/2 BCs and $\mathrm{L} 3 / 5 \mathrm{BCs}, y 0^{\prime}$ was omitted in all combined curve fits excepting $f-I$ slope, and $A^{\prime}$ was kept in the model for all compared variables, since all the experimental values at P12 differed between L1/2 BCs and L3/5 BCs. For each electrophysiological variable compared, the nls function in $\mathrm{R}$ software generates a $p$ value for the test of $\tau_{\mathrm{dev}}^{\prime}>0$, using a $t$ statistic $\hat{\tau} / \operatorname{se}(\hat{\tau})$, where $\hat{\tau}$ is the estimated value of $\tau_{\mathrm{dev}}$, and se is the SE of the estimator (approximated based on nonlinear least-squares theories). The statistic asymptotically follows a $t$ distribution under the null hypothesis, thus producing a test similar to a $t$ test for the coefficients in a linear regression model (Bates, 1988, 1992).

After performing the combined curve fits, we obtained a global comparison across physiological variables of the time constants of development $\tau_{\mathrm{dev}}$, by pooling the information from all the variables compared between a given pair of $\mathrm{PV}^{+}$neuron subtypes. For this global comparison, we used Fisher's method to combine $p$ values as follows: $X^{2}=-2 \Sigma_{i=1}^{k} \log P_{i}$ (Fisher, 1950; Won et al., 2009). Assuming independence of the individual tests, under the null hypothesis of no differences in $\tau_{\mathrm{dev}}$ for all $k$ variables, the combined statistic follows a $\chi^{2}$ distribution with degrees of freedom $2 k$. To account for correlations in individual tests, we adjusted Fisher's method based on a theoretical approximation of the null distribution, using a

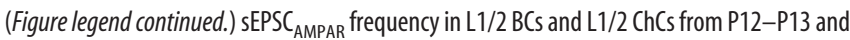
$P>30$ mice. Symbols the same as in $E$. Two-factor ANOVAs revealed a significant of effect of age $\left(F_{(1,36)}=14.826, p=0.0047\right)$ and cell type $\left(F_{(1,36)}=13.647, p=0.00073\right)$. Since $Q-Q$ plot and Shapiro-Wilk analysis revealed a deviation from normality of the $s E P S C_{\text {AMPAR }}$ frequency data, ANOVA was performed after log transformation of the data (Shapiro-Wilk $p=$ 0.748). At $P>30$, the sEPSC $C_{A M P A R}$ frequency was significantly lower in $L 1 / 2 C h C$ s versus $P>30$

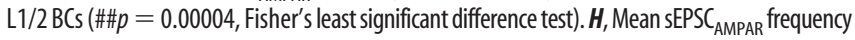
plotted as a function of postnatal age. The BC plot (gray symbols) was well fit by a single exponential function (thick black line), with a time constant $\tau_{\text {dev }}$ of $3.35 \pm 1.94 \mathrm{~d}$ (mean \pm SEfrom the nonlinear regression fit to the data). Shown are the $95 \%$ confidence bands of the curve fit for the $L 1 / 2 \mathrm{BC}$ data. The plot for ChCs (red symbols) could not be fit by an exponential function.
}

scaled $\chi^{2}$ distribution as originally described by Brown (Brown, 1975; Moskvina et al., 2011), with the correlations among all pairs of tests approximated from the original data.

\section{Results \\ ChCs and BCs have different laminar distribution since early postnatal development}

We targeted for recording $\mathrm{GFP}^{+}$neurons in acute slices from the PFC of G42 mice, in which GFP is expressed exclusively in $\mathrm{PV}^{+}$ neurons (Chattopadhyaya et al., 2004), and $\sim 90 \%$ of the $\mathrm{PV}^{+}$ cells in layers 2/3 are $\mathrm{GFP}^{+}$(Chattopadhyaya et al., 2004; Buchanan et al., 2012; Sippy and Yuste, 2013). In G42 mice, GFP ${ }^{+}$ neurons are detected by P0 (Chattopadhyaya et al., 2004), significantly earlier than the late postnatal onset of PV expression (Soriano et al., 1992; Del Río et al., 1994; Huang et al., 1999). In contrast, recombination in Pvalb ${ }^{C r e}$ mice labels only $\sim 5 \%$ of the $\mathrm{PV}^{+}$neurons by P13, and $\sim 30 \%$ by P19 (Carlén et al., 2012), paralleling the protracted developmental expression of PV. G42 mice are therefore a suitable model to assess $\mathrm{PV}^{+}$neuron development independent of age-dependent or activity-dependent changes in PV expression. We investigated $\mathrm{PV}^{+}$neurons starting at $\mathrm{P} 8$, because $\mathrm{ChC}$ migration from the ganglionic eminence, which appears to be delayed relative to $\mathrm{BC}$ migration (Inan et al., 2012; Taniguchi et al., 2013), is not complete until P7 (Taniguchi et al., 2013). To assess $\mathrm{PV}^{+}$neuron development, including the onset of puberty at $\sim$ P21 (Nelson et al., 1990; Laviola et al., 2003) and into adolescence, we studied G42 mice between P8 and $\sim$ P70

In the adult cortex, $\mathrm{PV}^{+}$neuron somata are found throughout layers 2-6 (Gabbott et al., 1997; Chattopadhyaya et al., 2004; Rymar and Sadikot, 2007; Bartolini et al., 2013). Because the laminar distribution of BCs and ChCs in the mouse PFC was not compared previously, we examined the morphology of $\mathrm{GFP}^{+}$ neurons with somata positioned across layers 2-5, filled with biocytin during recordings of excitatory synaptic currents, of intrinsic membrane properties, or both. We focused first on the PFC of $\mathrm{P} \geq 28$ mice, when ChCs and BCs are well-developed (Inan et al., 2012, 2013; Taniguchi et al., 2013; Tai et al., 2014). We found that 49 of $94 \mathrm{PV}^{+}$neurons with soma near the L1/2 border were ChCs (Fig. 1A) displaying abundant vertical cartridges of boutons (Fig. $1 A$, insets) in axonal arbors that branched densely below the soma, descending into layers 2 and 3, and, in some ChCs, also reaching layer 5 (Fig. $1 A$ ). All other L1/2 border $\mathrm{PV}^{+}$neurons (45 of 94) were BCs, with axonal arbors projecting mainly horizontally, nearly parallel to the L1/2 border, and with a few branches projecting into deeper layers in some BCs (Fig. 1B). The dendrites of the L1/2 ChCs mainly extended into layer 1 above the soma (Fig. 1C), whereas for most L1/2 BCs, the dendritic tree was more evenly distributed between layers 1 and 2 (Fig. 1C), as in the sensory cortex (Woodruff et al., 2011).

After finding that in the PFC of $\mathrm{P} \geq 28$ mice, both ChCs and $\mathrm{BCs}$ are present near the L1/2 border, we assessed the morphology of $\mathrm{PV}^{+}$neurons of layers 3 and 5. In previous work, embryonic recombination in $N k \times 2.1^{C r e E R}$ mice labeled numerous ChCs in deep cortical layers, which, however, were mostly PV-negative ( $\mathrm{PV}^{-}$; Taniguchi et al., 2013). In G42 mice, we found that all the $\mathrm{PV}^{+}$neurons recorded in PFC layers 3 and $5(n=25)$ were BCs (Fig. 1D). Measurements of the distance between the center of the soma and the pial surface for $109 \mathrm{GFP}^{+}$neurons (Fig. 1E) indicated that $\mathrm{ChC}$ somata are restricted to a short range of distances closely matching the L1/2 border, and are sometimes localized in deep layer 1, but excluded from deep layer 2, and from layers 3 and 5. In contrast, BCs are positioned throughout layers 2-5 (Fig. 
A
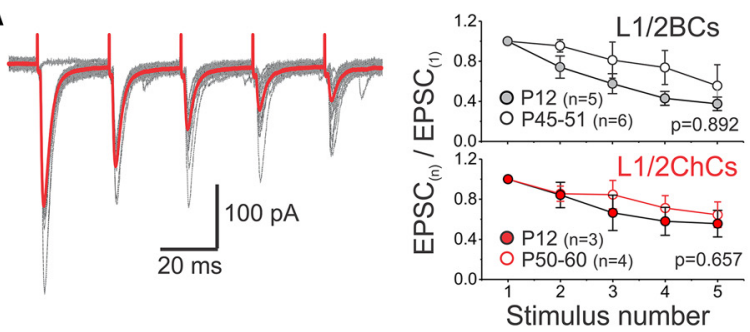

B
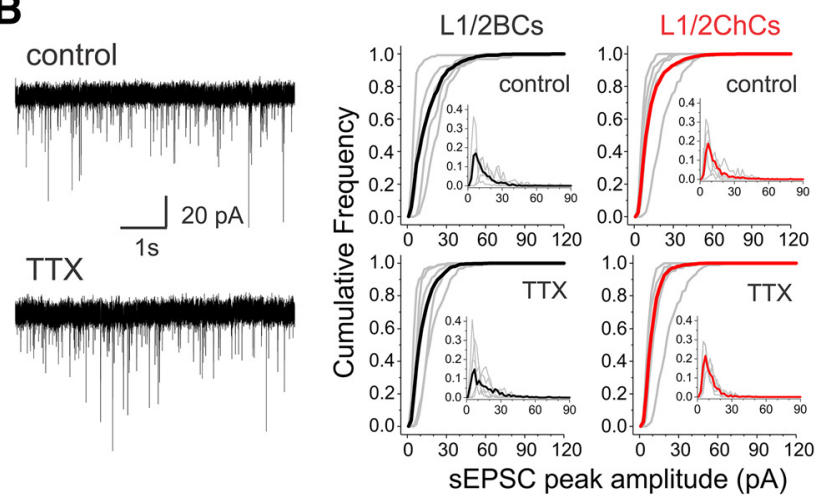

C
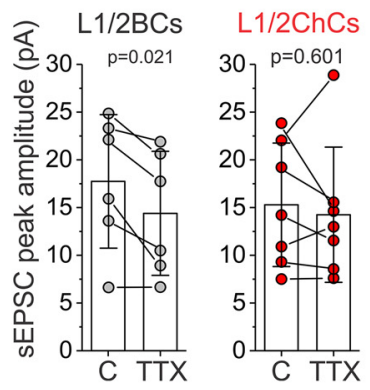

D
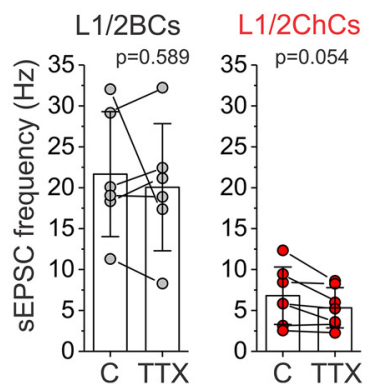

Figure 4. Short-term EPSC depression and effects of blocking network activity on sEPSCS recorded from $L 1 / 2 B C s$ and $L 1 / 2$ ChCs. $A$, Left, Examples of EPSC trains illustrating short-term depression. Shown are consecutive traces superimposed (gray) and their average (red). The EPSC trains were evoked in a L1/2 BC by focal extracellular stimulation applied to layer 1 (five stimuli at $40 \mathrm{~Hz}$ ). Right, Plots of EPSC amplitude for each stimulus number, normalized to the amplitude of EPSC $C_{(1)}$ in each train. Shown are means \pm SEM. The EPSC ${ }_{(5)} /$ EPSC $_{(1)}$ values showed deviation from normality based on Q-Q plot and Shapiro-Wilk test analysis. EPSC $C_{(5)} /$ EPSC $_{(1)}$ were compared with Student's $t$ tests performed after log transformation of the data (ShapiroWilk $p=0.555) . \mathrm{L} 1 / 2 \mathrm{BC}, t_{(9)}=0.139, p=0.892 ; \mathrm{L} 1 / 2 \mathrm{ChCs}, t_{(5)}=0.475, p=0.657 . B$, Left, Example of recordings of sEPSCs from a L1/2 BC (P42) before (top) and after (bottom) the addition of $1 \mu \mathrm{M}$ TTX. Right, Cumulative frequency distribution of $\mathrm{SEPSC}_{\mathrm{AMPAR}}$ peak amplitude before (control) and after application of $1 \mu \mathrm{M}$ TTX for L1/2 BCs and L1/2 ChCs. Insets show binned histograms as in Figure 3. C, Summary plots of sEPSC AMPAR $_{\text {amplitude before and after }}$ TTX application to L1/2 BCs (left) and L1/2 ChCs (right). Shown are the $p$ values from paired Student's $t$ tests comparing sEPSC amplitude before and after TTX application. L1/2 BCs, $t_{(5)}=$ $3.3, p=0.0210 ; \mathrm{L} 1 / 2 \mathrm{ChC}, t_{(6)}=0.55, p=0.601$. $D$, Summary plots of $s \mathrm{EPSC}_{\mathrm{AMPAR}}$ frequency before and after TTX application to L1/2 BCs (left) and L1/2 ChCs (right). Shown are the $p$ values from paired $t$ tests comparing sEPSC amplitude before and after TTX application. L1/2 BCs, $t_{(5)}=0.58, p=0.589 ; \mathrm{L} 1 / 2 \mathrm{ChCs}, t_{(6)}=2.38, p=0.054$.

$1 E)$. While these data suggest that $\mathrm{PV}^{+} \mathrm{ChCs}$ and $\mathrm{BC}$ s have markedly different laminar distributions, it is possible that $\mathrm{PV}^{+} \mathrm{ChCs}$ were not targeted for recording in layers 3 and 5, because not all $\mathrm{PV}^{+}$neurons are $\mathrm{GFP}^{+}$in the G42 mouse cortex (Chattopadhyaya et al., 2004; Buchanan et al., 2012; Sippy and Yuste, 2013). Hence, to assess the laminar distribution of $\mathrm{PV}^{+} \mathrm{ChCs}$ and $\mathrm{BCs}$ independent of the incomplete GFP labeling in G42 mice, we crossed Pvalb ${ }^{C r e}$ mice with the Ai14 knock-in reporter line, to derive $P$ valb ${ }^{C r e}$;Ai14 mice, which express the red fluorescent pro- tein tdTomato in $\mathrm{PV}^{+}$cells. In the PFC of $\mathrm{P} \geq 28$ Pvalb $^{\text {Cre }}$;Ai14 mice, the laminar distribution of tdTomato-positive ChCs and BCs (Fig. $1 F$ ) was very similar to the distribution of $\mathrm{GFP}^{+} \mathrm{ChCs}$ and $\mathrm{BCs}$ in $\mathrm{P} \geq 28 \mathrm{G} 42$ mice (Fig. $1 E$ ). Thus, data from two separate mouse lines indicate that in the PFC of $\mathrm{P} \geq 28$ mice, $\mathrm{PV}^{+}$BCs populate layers 2-5, but ChCs are found only near the $\mathrm{L} 1 / 2$ border. The somata of the L1/2 border ChCs and BCs (L1/2 ChCs and L1/2 BCs, respectively), and of the layers 3 and 5 BCs (L3/5 BCs) were distributed across cytoarchitectonic regions of the medial frontal cortex (Fig. $1 G$ ), suggesting the distinct laminar distribution of ChCs versus BCs is common to all areas.

After characterizing the laminar distribution of BCs and ChCs in the PFC of $\mathrm{P} \geq 28$ mice, we assessed the morphology of developing $\mathrm{PV}^{+}$neurons, starting at P8, and focusing first on $\mathrm{GFP}^{+}$ neurons with soma near the L1/2 border. We found that many of these $\mathrm{PV}^{+}$neurons had properties resembling L1/2 BCs, with axonal arbors extending horizontally (Fig. 2A), and dendrites evenly distributed between layers 1 and 2 (Fig. 2C). The other immature $\mathrm{L} 1 / 2$ border $\mathrm{PV}^{+}$neurons had axo-dendritic tree features quite distinct from those of BCs, and similar to L1/2 ChCs. However, in most of the L1/2 ChC-like immature $\mathrm{PV}^{+}$neurons, axon cartridges were absent, and cartridges were detected starting at P12, although in small numbers (Fig. $2 B$ ). The cartridge number increased markedly by P13-P15, and continued developing through the first 4 postnatal weeks (Fig. 2B).

Next, we characterized the morphology of $\mathrm{GFP}^{+}$cells in layers 3 and 5 of the $\mathrm{P} 8-\mathrm{P} 17 \mathrm{PFC}$, and found that all the $\mathrm{PV}^{+}$neurons in these layers (28 of 28) had features consistent with BCs (Fig. $2 D)$, and did not display axon cartridges. Measures of the distance between the pia and the soma of all the $\mathrm{PV}^{+}$neurons from the developing PFC (P12-P17) revealed laminar distributions (Fig. 2E) similar to those observed in the $\mathrm{P} \geq 28 \mathrm{PFC}$ (Fig. 1E,F). Moreover, the distribution of ChCs and BCs across subregions of the developing PFC (Fig. 2F) was consistent with that observed in the $\mathrm{PFC}$ of $\mathrm{P} \geq 28$ mice (Fig. $1 G$ ).

Since ChCs were identified by the presence of axon cartridges first by $\mathrm{P} 12$, and were restricted to the L1/2 border, we focused on $\mathrm{L} 1 / 2$ border $\mathrm{PV}^{+}$neurons in the $\mathrm{PFC}$ of $\mathrm{P} \geq 12$ mice to compare the physiological maturation of ChCs and BCs independent of potential layer-related differences. To investigate whether $\mathrm{BC}$ maturation differs between layers, we compared L1/2 BCs with L3/5 BCs.

\section{Excitatory synaptic inputs follow different maturation trajectories in ChCs and BCs}

To contrast the maturation trajectory of excitatory synapses in L1/2 ChCs with L1/2 BCs, we recorded spontaneous EPSCs (sEPSCs). In both $\mathrm{PV}^{+}$cell subtypes, the sEPSCs recorded while holding the membrane potential near rest $(-70 \mathrm{mV})$ were blocked by CNQX, an AMPA receptor antagonist (Fig. $3 A$ ). Moreover, the AMPA receptor-mediated sEPSCs ( sEPSC $_{\text {AMPAR }}$ ) had very similar features in L1/2 ChCs and L1/2 BCs (Fig. 3B). Specifically, the sEPSC $_{\text {AMPAR }}$ peak amplitude did not change with age in $\mathrm{L} 1 / 2$ BCs or L1/2 ChCs (Fig. 3C-F), and it was slightly but significantly smaller in L1/2 ChCs (Fig. $3 E$ ). In L1/2 BCs, the EEPSC $_{\text {AMPAR }}$ frequency was low at $\mathrm{P} 12$, and increased significantly with age (Fig. 3G). In contrast, L1/2 ChCs also had low sEPSC AMPAR $_{\text {fre- }}$ quency at P12, but the frequency did not change with age (Fig. $3 G$ ). The increase of sEPSC $C_{\text {AMPAR }}$ frequency in L1/2 BCs followed a rapid time course well fit by a single exponential decay function (see Materials and Methods), with a developmental time constant $\tau_{\mathrm{dev}}$ of $3.35 \pm 1.94 \mathrm{~d}$ (mean $\pm \mathrm{SE}$ from the nonlinear regression), reaching plateau levels by $\sim$ P20 (Fig. $3 H$ ). The plateau levels of 
A

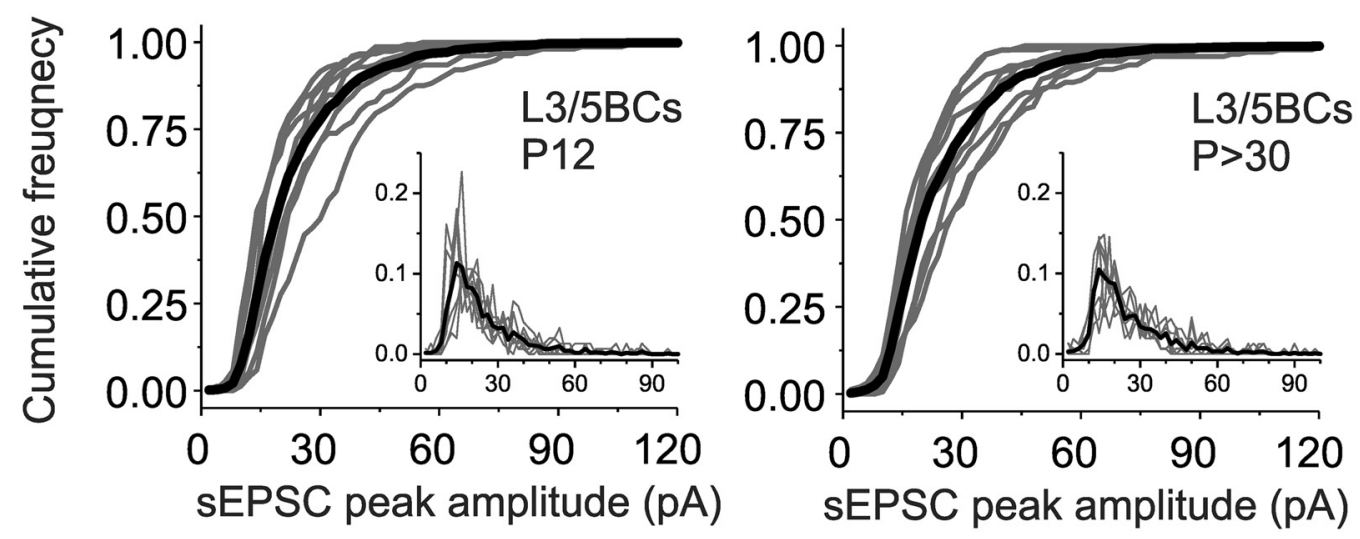

B
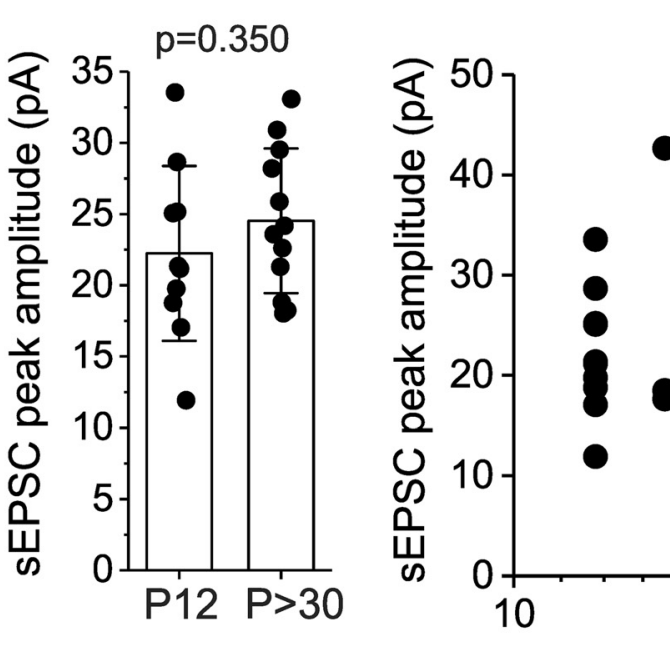

L3/5BCs

C
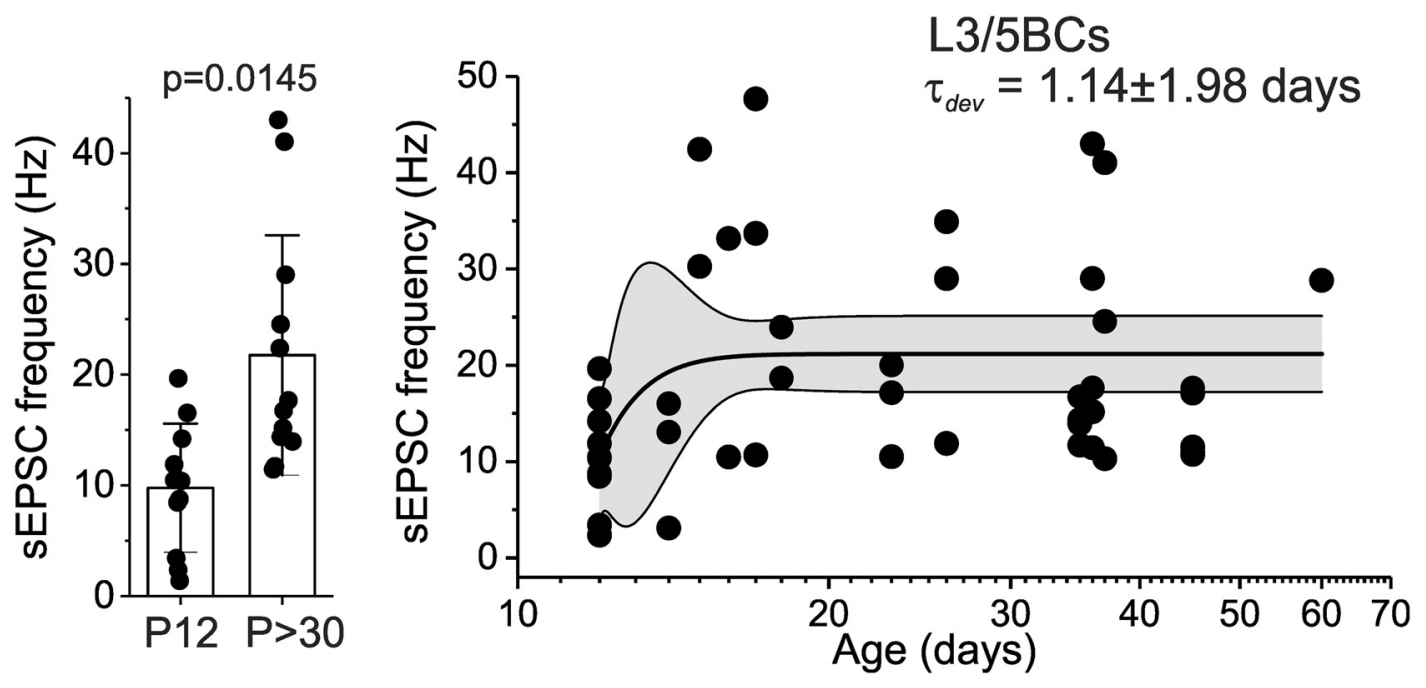

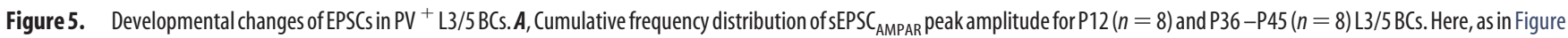

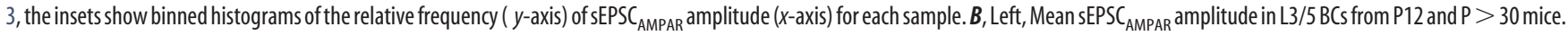
Student's $t$ test analysis showed absence of difference between age groups $\left(t_{(20)}=0.955, p=0.350\right)$. Right, Plot of mean $\mathrm{sEPSC}_{\text {AMPAR }}$ amplitude as a function of postnatal age. Each data point represents a single PV neuron. C, Left, Mean sEPSC $C_{\text {AMPAR }}$ frequency in BCs and ChCs from P12 and P35-P38 mice. Student's $t$ test analysis showed a significant increase with age $\left(t_{(20)}=3.251, p=\right.$ 0.0040). Q-Q plot and Shapiro-Wilk analysis revealed a deviation from normality of the SEPSC $_{\text {AMPAR }}$ frequency. Thus, the $t$ test was performed after log transformation (Shapiro-Wilk $p=0.283$ ).

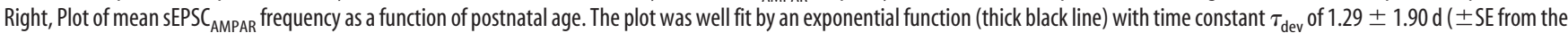
nonlinear regression). Shown are the $95 \%$ confidence bands of the curve fit. 
SEPSC $_{\text {AMPAR }}$ frequency were 3-4 times higher in $\mathrm{L} 1 / 2$ BCs compared with $\mathrm{L} 1 / 2$ ChCs (Fig. 3G,H). These data show that divergent trajectories of early development produce significant differences in excitatory input onto $\mathrm{L} 1 / 2 \mathrm{ChCs}$ versus L1/2 BCs, which are already established by $\sim$ P20, near the onset of puberty.

The age-related increase in $\mathrm{SEPSC}_{\mathrm{AM}^{-}}$ PAR frequency in L1/2 BCs may be due to higher glutamate release probability $(\mathrm{Pr})$, higher activity in a local network evoking EPSCs selectively in L1/2 BCs, or to increasing numbers of glutamate synapses in L1/2 BCs. To examine if Pr changes with age in L1/2 BC synapses, we measured short-term depression of EPSCs evoked by repetitive presynaptic stimulation. At synapses on $\mathrm{PV}^{+}$neurons, $\mathrm{Pr}$ and EPSC depression are positively correlated (Koester and Johnston, 2005; Yang et al., 2013; Lu et al., 2014). Hence, if at synapses on L1/2 BCs Pr increases with age, then EPSC depression should increase with age as well. To test this prediction, we measured short-term depression of EPSCs evoked in L1/2 BCs or L1/2 ChCs by focal extracellular stimulation (five stimuli at $40 \mathrm{~Hz}$ ) with electrodes placed in layer 1 , to activate excitatory inputs predominantly in this layer, where both $\mathrm{L} 1 / 2 \mathrm{BC}$ and $\mathrm{L} 1 / 2$ ChC dendrites project substantially. We found that EPSCs displayed short-term depression in both $\mathrm{L} 1 / 2 \mathrm{BCs}$ and $\mathrm{L} 1 / 2$ ChCs in the PFC of P12-P13 or P45-P60 G42 mice (Fig. 4A). However, the magnitude of EPSC depression did not increase with age (Fig. 4A), indeed showing a decreasing trend, as reported for sensory cortex $\mathrm{PV}^{+}$neurons (Miao et al., 2016). These results therefore argue against an age-related increase of $\operatorname{Pr}$ at L1/2 BC synapses.

If the age-related increase of SEPSC $_{\mathrm{AMPAR}}$ frequency in $\mathrm{L} 1 / 2$ $\mathrm{BCs}$ depends on increasing levels of network activity, then the sEPSC $_{\text {AMPAR }}$ frequency in L1/2 BCs should be reduced when network activity is blocked. To test this prediction, in the PFC of P28-P42 G42 mice, when sEPSC AMPAR $_{\text {frequency reached }}$ age-related plateau (Fig. $3 G, H$ ), we recorded $s$ PSC $_{\mathrm{AMPAR}}$ from L1/2 BCs or L1/2 ChCs before and after applying $1 \mu \mathrm{M}$ TTX to inhibit network activity (Fig. $4 B$ ). We found that in L1/2 BCs and L1/2 ChCs, TTX had small effects on sEPSC $\mathrm{AM}^{-}$ PAR amplitude (Fig. 4C) and frequency (Fig. 4D). Moreover, the frequency of miniature $\mathrm{EPSC}_{\mathrm{AMPAR}}$, recorded in the presence of TTX, was higher in L1/2 BCs compared with L1/2 ChCs (Fig. 4D). These data thus suggest that the increase of sEP$\mathrm{SC}_{\mathrm{AMPAR}}$ frequency in $\mathrm{L} 1 / 2 \mathrm{BCs}$ is unrelated to an age-related increase in network activity.

We next assessed excitatory synapse maturation in L3/5 BCs, and found age-related changes in SEPSC $_{\mathrm{AMPAR}}$ very similar to those observed in L1/2 BCs. For example, the mean $s$ EPSC $_{\text {AMPAR }}$ amplitude did not change with age (Fig. $5 A$ ), and, moreover, did not differ from those of L1/2 BCs at P12 $\left(t_{(17)}=0.186, p=0.854\right)$
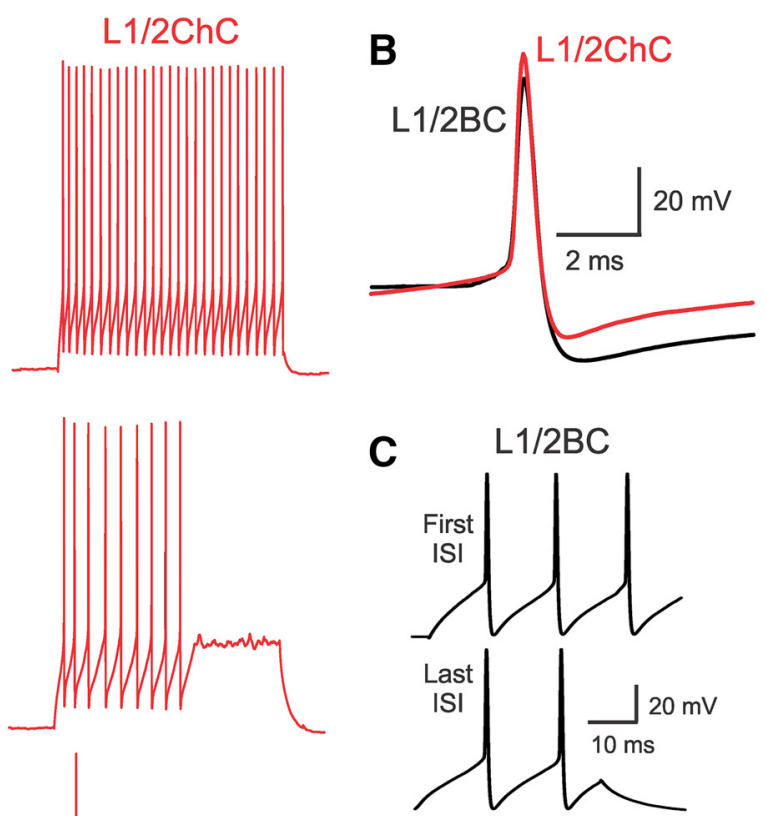

\section{$\mathrm{L} 1 / 2 \mathrm{ChC}$}

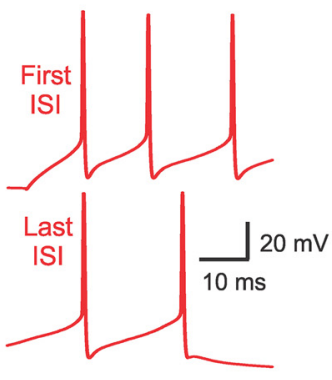

Figure 6. Intrinsic physiological properties of mature $\mathrm{L} 1 / 2 \mathrm{BCs}$ and $\mathrm{L} 1 / 2 \mathrm{ChC}$. $A$, Examples of membrane potential responses in L1/2 BCs (black traces) and L1/2 ChCs (red traces), elicited by injection of four current steps of increasing amplitude, shown in blue at the bottom. Note the longer delay to fire the first $\mathrm{AP}$ in the $\mathrm{L} 1 / 2 \mathrm{BC}$ compared with the $\mathrm{L} 1 / 2 \mathrm{ChC}$ at $/$ threshold (second traces from B, Superimposed traces of single APs, showing nearly identical duration, and smaller AHP in the $\mathrm{L} 1 / 2 \mathrm{ChC}$ compared with the L1/2 BC. C, Examples illustrating the first ISI (top) and last ISI (bottom) for examples of L1/2 BCs and L1/2 ChCs. Note the substantially longer duration of the last ISI compared with the first ISI in the L1/2 ChC.

or at $\mathrm{P} \geq 28\left(t_{(24)}=0.885, p=0.385\right)$. The sEPSC $_{\mathrm{AMPAR}}$ frequency in $\mathrm{L} 3 / 5 \mathrm{BCs}$ was low at P12, but was $\sim 66 \%$ higher compared with $\mathrm{P} 12 \mathrm{~L} 1 / 2 \mathrm{BCs}\left(t_{(17)}=1.80, p=0.044\right)$. After P12, the sEPSC $_{\text {AMPAR }}$ frequency in L3/5 BCs increased rapidly with age (Fig. $5 B$ ), reaching plateau levels that did not differ $\left(t_{(24)}=0.320\right.$, $p=0.751$ ) from those in L1/2 BCs (Fig. $3 E, G$ ). The rapid increase

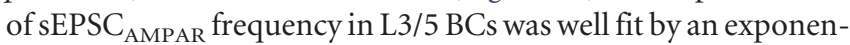
tial function (Fig. $5 B$ ), with a time constant that had a smaller value $\left(\tau_{\mathrm{dev}}=1.29 \pm 1.90 \mathrm{~d}\right)$ compared with L1/2 BCs $\left(\tau_{\mathrm{dev}}=\right.$ $3.35 \pm 1.94 \mathrm{~d})$, although both parameters displayed substantial $\mathrm{SE}$. To test whether the $\mathrm{SEPSC}_{\mathrm{AMPAR}}$ frequency changed between P12 and plateau value at different rates in L1/2 versus L3/5 BCs, we assessed the significance of differences in $\tau_{\mathrm{dev}}$. To test whether the time constants $\tau_{\mathrm{dev}}$ of two separate exponential decay functions fit to the data are significantly different (see Materials and Methods), we used a statistical model that combines in a single curve fitting session the data from the two samples under comparison. With this approach, we found that $\tau_{\mathrm{dev}}$ of $\mathrm{SEPSC}_{\mathrm{AMPAR}}$ frequency did not differ between L1/2 and L3/5 BCs $\left(t_{(105)}=\right.$ $1.306, p=0.097)$. These data show that the sEPSC frequency increases with similar exponential rates in L1/2 and L3/5 BCs, but 
A
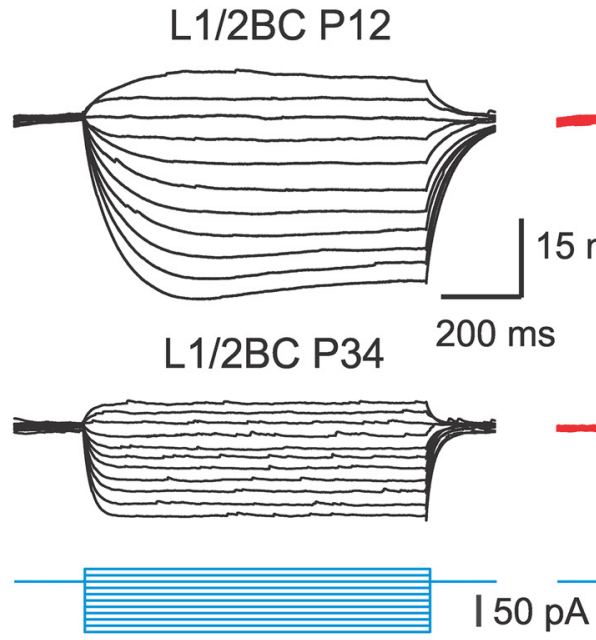

B

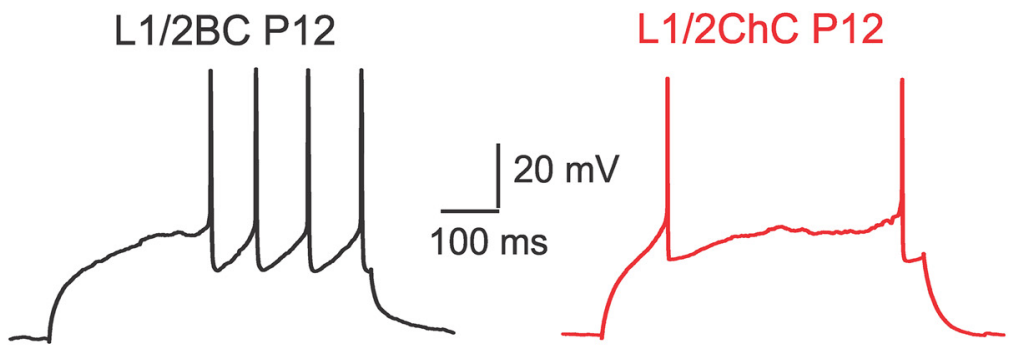

C

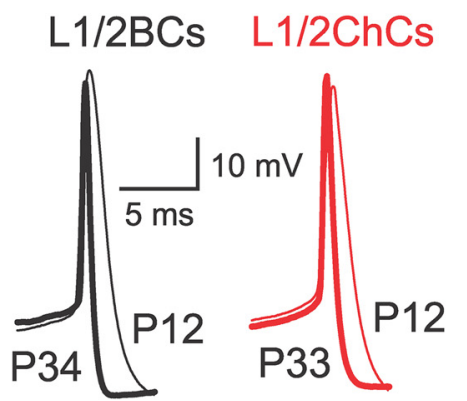

D

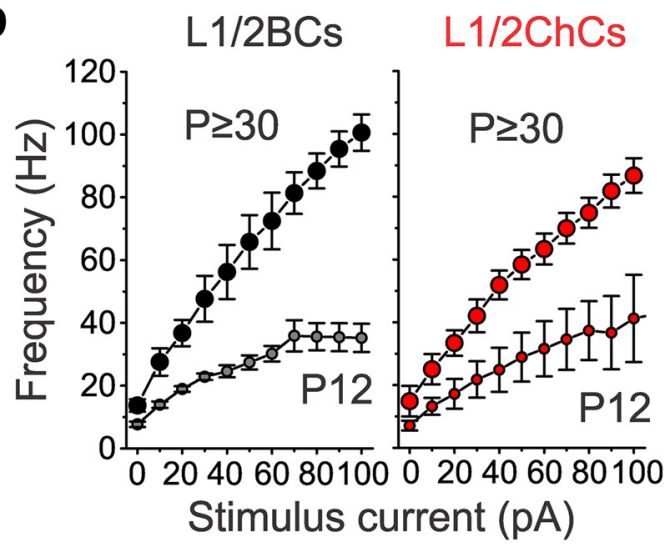

Figure 7. Development of the intrinsic physiological properties of $\mathrm{L} 1 / 2 \mathrm{BC}$ and $\mathrm{L} 1 / 2 \mathrm{ChCs}$. $A$, Examples of subthreshold membrane potential responses of $\mathrm{P} 12$ (top) and mature (bottom) $\mathrm{L} 1 / 2 \mathrm{BCs}$ (black) and $\mathrm{L} 1 / 2 \mathrm{ChCs}$ (red). Identical families of current steps (blue) were injected into each $\mathrm{PV}^{+}$neuron. $\boldsymbol{B}$, Example recordings showing differences between $\mathrm{L} 1 / 2 \mathrm{BCs}$ and $\mathrm{L} 1 / 2 \mathrm{ChCs}$ in the delay to fire the first AP at P12.C, Superimposed traces of single APs recorded from $P 12$ (thin lines) and mature (thick lines) $L 1 / 2 B C S$ (black) and $\mathrm{L} 1 / 2 \mathrm{ChCs}$ (red). Note that in both $\mathrm{PV}^{+}$neuron subtypes, the AP duration shortened significantly with age. $D, f-/$ plots for $P 12$ and mature $L 1 / 2 B C s$ and $L 1 / 2 C h C s$. Note the increase with age in the slope of the linear portion of the $f-/$ relation for both $\mathrm{PV}^{+}$neuron subtypes. Shown are means $\pm \mathrm{SEM}$.

starting from a P12 value closer to the plateau in L3/5 BCs than in $\mathrm{L} 1 / 2$ BCs. Since the developmental increase in $\mathrm{sEPSC}_{\mathrm{AMPAR}}$ frequency likely starts before P12, the higher EPSC frequency in L3/5 BCs at P12 is consistent with an earlier onset of excitatory synapse maturation in L3/5 versus L1/2 BCs. Our analysis of the developmental trajectory of excitatory inputs therefore suggests that plateau levels of excitatory drive are reached around P20, before or very close to the onset of puberty, in all $\mathrm{PV}^{+}$neurons across layers 2-5.
Intrinsic membrane properties follow distinct maturation trajectories in ChCs and BCs

If the time course of excitatory synaptic input development reflects the overall maturation trajectory of each $\mathrm{PV}^{+}$neuron subtype, then the FS phenotype should mature earlier in L1/2 ChCs, in which excitatory inputs show mature-like properties by $\mathrm{P} 12$, compared with $\sim \mathrm{P} 20$ in $\mathrm{L} 1 / 2$ and $\mathrm{L} 3 / 5$ BCs. However, in L1/2 ChCs the excitatory drive did not increase with age, contrasting with the rapid increase in BCs. Because FS properties are thought to develop in an activity-dependent manner (Miller et al., 2011; Okaty and Nelson, 2013; Dehorter et al., 2015), the developmental increase of excitatory drive in BCs may produce an earlier maturation of FS properties in BCs compared with ChCs. Hence, we assessed 10 electrophysiological variables contributing to the FS phenotype in $\mathrm{PV}^{+}$neurons from the PFC of G42 P $\geq 12$ mice.

First, we defined the physiological properties of $\mathrm{L} 1 / 2$ border $\mathrm{PV}^{+}$neurons at $\mathrm{P} \geq$ 30 , when sEPSC features reached agerelated plateau (Fig. 3). We found that both L1/2 BCs and L1/2 ChCs displayed APs with short duration at half maximal amplitude (AP half-width), large AHP, and sustained high-frequency firing with small spikefrequency adaptation, a crucial feature of the FS phenotype (Fig. 6A,B). However, some variables differed between $\mathrm{L} 1 / 2 \mathrm{BCs}$ and L1/2 ChCs, as shown previously (Woodruff et al., 2009; Povysheva et al., 2013; Taniguchi et al., 2013). For instance, compared with L1/2 ChCs, L1/2 BCs had lower $R_{\text {in }}$, higher $I$ threshold, and delayed firing of the first AP (first AP delay) with stimulation near $I$ threshold (Fig. 6A). Moreover, L1/2 ChCs had smaller AHP amplitude (Fig. 6B) and stronger spikefrequency adaptation (Fig. $6 C$ ).

Next, we assessed the electrophysiological properties of $\mathrm{PV}^{+}$cells at $\mathrm{P} 12$, and compared them with those of $\mathrm{P} \geq$ 30 neurons. We found that, at P12, most features were inconsistent with the FS phenotype, showing that FS properties emerge after P12. Moreover, at P12, L1/2 BCs and L1/2 ChCs had very similar electrophysiological properties (Fig. 7), and only the first AP delay differed between subtypes at this age (Fig. $7 B$ ). Most properties changed with age, including the AP half-width (Fig. $7 C$ ) and the $f-I$ slope (Fig. $7 D$ ), which did not differ between mature L1/2 BCs and L1/2 ChCs. Twofactor ANOVA and post hoc comparison analysis (Fig. 8) revealed significant changes with age for most variables and divergent developmental changes, since only one parameter differed between L1/2 BCs and L1/2 ChCs at P12, but seven parameters differed at $\mathrm{P} \geq 30$ (Fig. 8). 


\section{O L1/2BCs O L1/2ChCs}
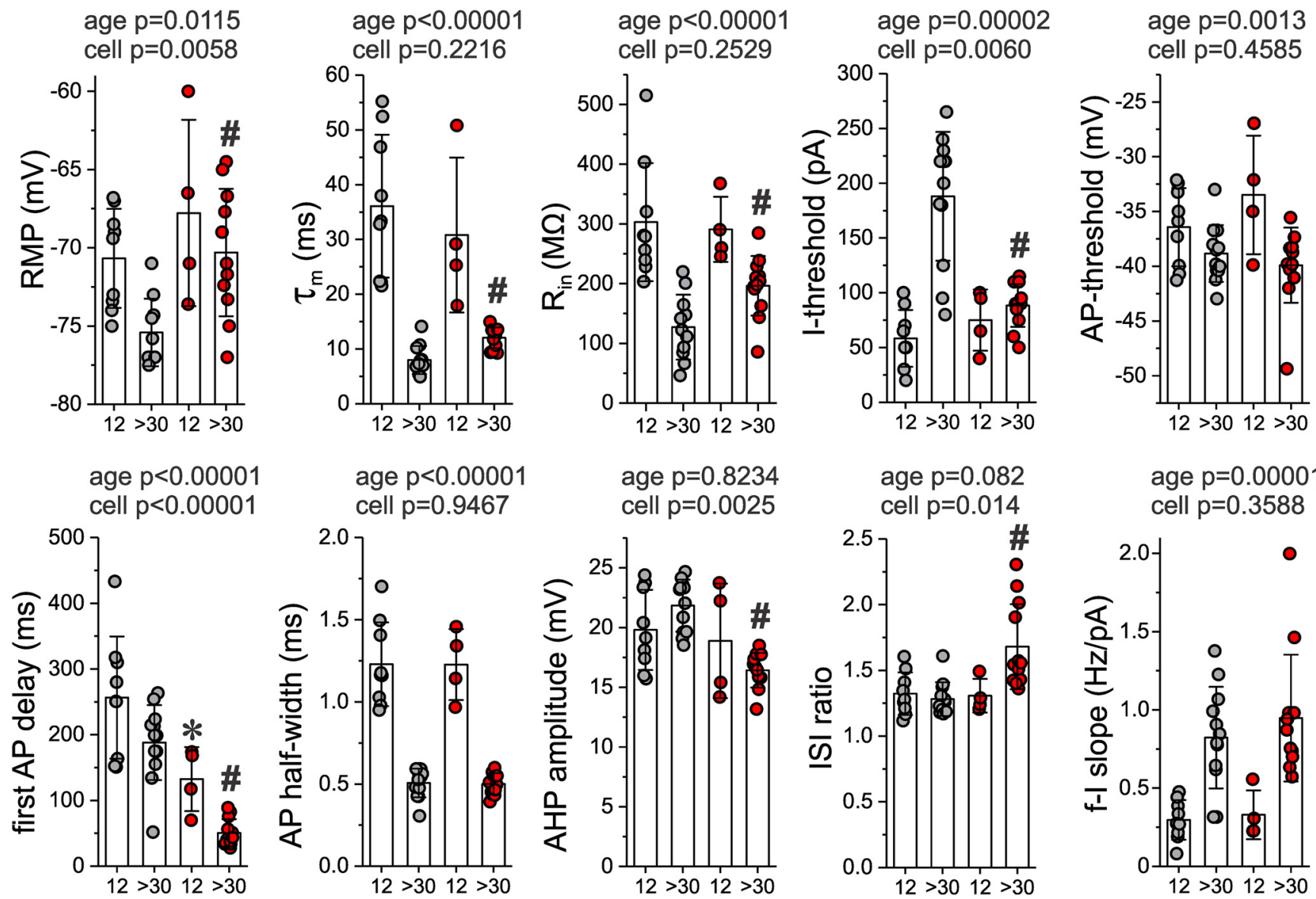

age $p=0.00001$

cell $p=0.3588$

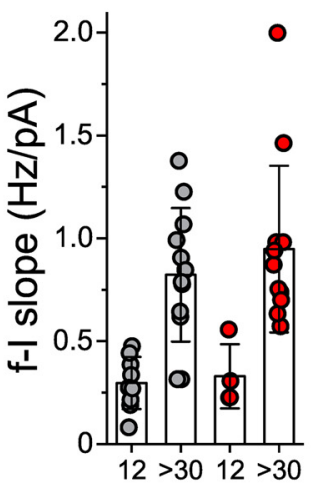

Figure 8. Developmental changes in the intrinsic membrane properties of $L 1 / 2 \mathrm{BC}$ and $\mathrm{L} 1 / 2 \mathrm{ChCs}$. The graphs summarize (mean $\pm \mathrm{SD}$ ) the data of 10 electrophysiological variables contributing to the $F S$ phenotype of $L 1 / 2 B C s$ and $L 1 / 2 \mathrm{ChCs}$, measured from a sample of GFP ${ }^{+} \mathrm{PV}^{+}$neurons from $\mathrm{P} 12$ and $\mathrm{P}>30 \mathrm{G} 42$ mice, when all variables reach age-related plateaus. Shown above each graph are the $p$ values from two-factor ANOVA tests of the effect of age and cell type. The $F$ statistic values for age and cell type were, respectively, as follows: resting membrane potential (RMP): $F_{(1,30)}=$ $7.25,8.84 ; \tau_{\mathrm{m}}: F_{(1,33)}=119.7,1.551 ; R_{\mathrm{in}}: F_{(1.32)}=30.3,1.36 ;$ / threshold: $F_{(1.33)}=25.6,8.63 ;$ AP threshold: $F_{(1.33)}=12.4,0.563 ;$ first AP delay: $F_{(1,33)}=19.52,46.22 ;$ AP half-width: $F_{(1.33)}=166$, 0.0045; AHP amplitude: $F_{(1,33)}=0.050,10.7 ;$ ISI ratio: $F_{(1,33)}=4.53,6.50 ; f-I$ slope: $F_{(1,33)}=41.2,0.8666$. ${ }^{*}$, Significant difference between P12 L1/2 BCs and L1/2 ChCs; \#, significant difference between $\mathrm{P}>30 \mathrm{~L} 1 / 2 \mathrm{BCs}$ and L1/2 ChCs, Fisher's least significant difference post hoc tests. Q- $Q$ plot and Shapiro-Wilk analysis revealed deviation from normality of four variables, for which the ANOVA was performed after log transformation (Shapiro-Wilk: $\tau_{m^{\prime}} p=0.357$; first AP delay, $p=0.164 ; \mid I S$ ratio, $p=0.017 ; f-I$ slope, $p=0.190$ ). For the ISI ratio, we performed the ANOVA on the data ranks, with the following results: age, $F_{(1,33)}=3.214, p=0.082$; cell type: $F_{(1,33)}=6.788, p=0.014$. The $p$ values of the Fisher's least significant difference tests were as follows: RMP, $\mathrm{P} 12 p=0.1929, \mathrm{P}>30 p=0.003 ; \tau_{\mathrm{m}}, \mathrm{P} 12 p=0.570, \mathrm{P}>30 p=0.00002 ; R_{\text {in }}, \mathrm{P} 12 p=0.767, \mathrm{P}>30 p=0.019 ; /$ threshold, $\mathrm{P} 12 p=0.481, \mathrm{P}>30 p<0.00001 ; \mathrm{AP}$ threshold, $\mathrm{P} 12 p=$ $0.165, \mathrm{P}>30 p=0.456$; first AP delay, $\mathrm{P} 12 p=0.0015, \mathrm{P}>30 p<0.00001 ;$ AP half-width, $\mathrm{P} 12 p=0.984, \mathrm{P}>30 p=0.928 ;$ AHP amplitude, $\mathrm{P} 12 p=0.570, \mathrm{P}>30 p=0.00002 ; \mid \mathrm{ISI}$ ratio, $\mathrm{P} 12 p=0.952, \mathrm{P}>30 p=0.000041 ; f-I$ slope, $\mathrm{P} 12 p=0.862, \mathrm{P}>30 p=0.330$.

We studied L1/2 BC and L1/2 ChC development in G42 mice, because very few $\mathrm{PV}^{+}$neurons are labeled before $\mathrm{P} 20$ by, for instance, Cre-mediated recombination in $\mathrm{Pvalb}^{\mathrm{Cre}}$ mice (Carlén et al., 2012). However, we also recorded from some mature $\mathrm{L} 1 / 2$ BCs and L1/2 ChCs from Pvalb ${ }^{C r e}$;Ail4 mice (Fig. $1 F$ ). Thus, we compared the physiological properties of L1/2 BCs and L1/2 ChCs from Pvalb ${ }^{\text {Cre }}$; Ai14 and G42 mice, comparing our Pvalb ${ }^{\mathrm{Cre}}$; $\mathrm{Ail} 4$ neuron sample with a subset of $\mathrm{PV}^{+}$neurons from G42 mice of matching age range. As shown in Figure 9, two-factor ANOVA revealed significant effects of cell type (L1/2 BCs vs L1/2 ChCs) that were comparable to those found in G42 mice (Fig. 8). Moreover, mouse line (G42 vs Pvalb ${ }^{\text {Cre }}$;Ai14) showed a lack of effect for most (9 of 10) electrophysiological variables (Fig. 9). These results, together with data from other mouse lines (Woodruff et al., 2009; Taniguchi et al., 2013), and from rat PFC (Povysheva et al., 2013), suggest that several physiological properties distinguish mature L1/2 BCs and L1/2 ChCs in general, and not specifically in particular mouse lines.
The data in Figure 8 show that most variables contributing to the FS phenotype change significantly between $\mathrm{P} 12$ and $\mathrm{P} \geq 30$, but do not assess the maturation rate of these variables, nor whether the rate differs between L1/2 BCs and L1/2 ChCs. Thus, next, we assessed the developmental trajectories of the electrophysiological variables showing significant age effect, applying single exponential curve fitting (Fig. 10). Some variables, such as the AP half-width and $\tau_{\mathrm{m}}$, seemed more closely regulated by age, showing rapid developmental trajectories well fit by the exponential functions (Fig. 10). In contrast, other variables measured from the same sample of neurons, such as the $f-I$ slope, $R_{\text {in }}$, and $I$ threshold, showed larger variability, and some of these other variables could not be fit by exponential functions (Fig. 10). Hence, to compare the maturation rate of the FS phenotype in L1/2 BCs and $\mathrm{L} 1 / 2 \mathrm{ChCs}$, assessed via the exponential time constant $\tau_{\mathrm{dev}}$, we focused on the four variables that showed age-related changes, and were fit by single exponential functions in both $\mathrm{PV}^{+}$neuron subtypes (Fig. 10). For these variables, except $\tau_{\mathrm{m}}$, the values at 


\section{O L1/2BCs O L1/2ChCs}
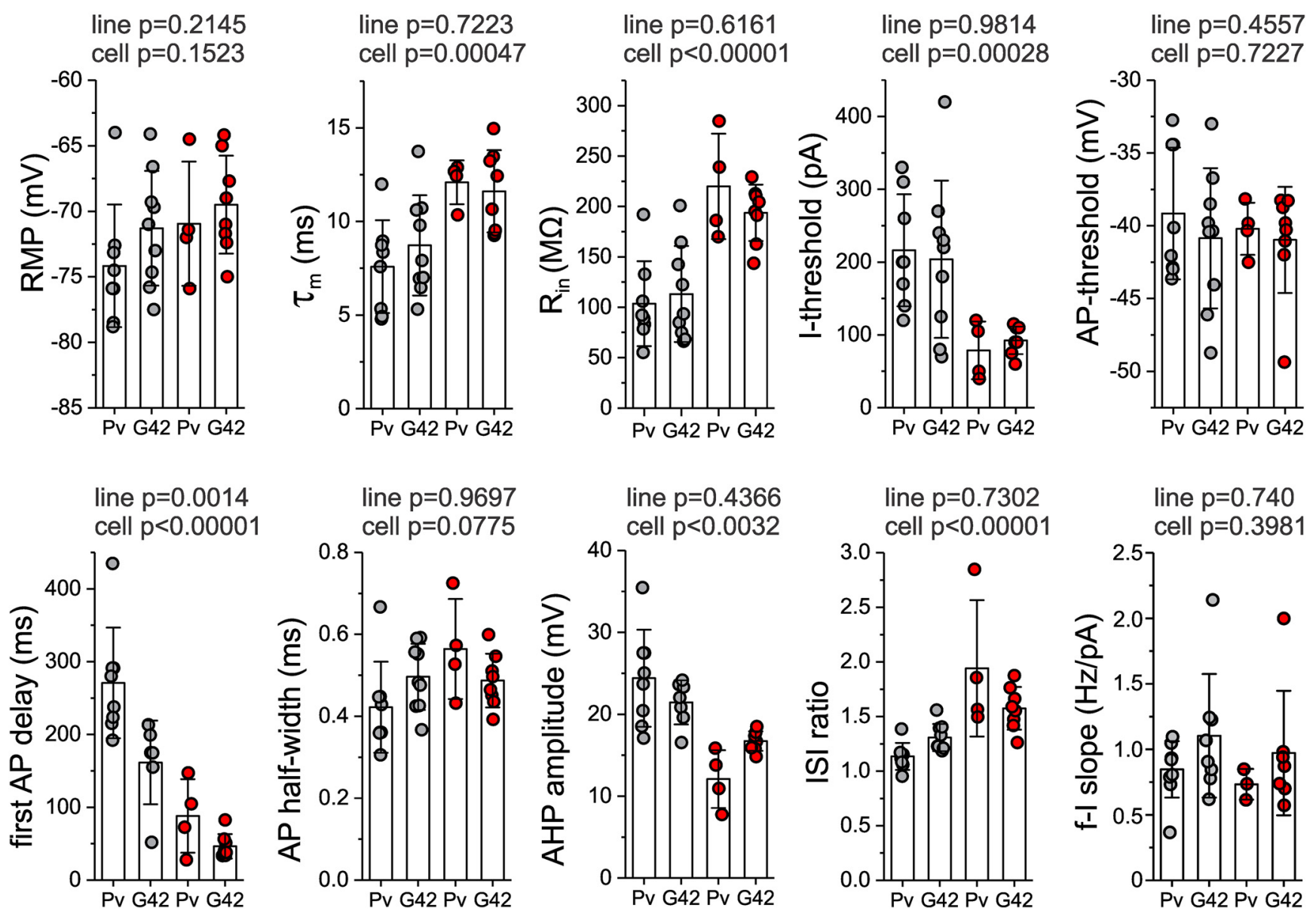

Figure 9. Intrinsic membrane properties of mature L1/2 BCs and L1/2 ChCs from G42 versus Pvalb ${ }^{\text {Cre } ; A i 14 ~ m i c e ~(P v) . ~ T h e ~ g r a p h s ~ s u m m a r i z e ~(m e a n ~} \pm$ SD) the data of 10 electrophysiological

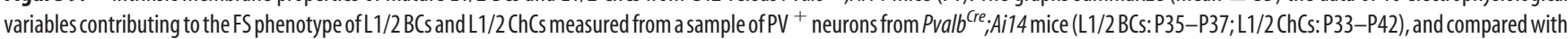
a subset of the GFP ${ }^{+} \mathrm{PV}^{+}$neurons matched by age (L1/2 BCs: P34-P50; L1/2 ChCs: P33-P43). Shown above each graph are the $p$ values from two-factor ANOVA tests of the effect of mouse line and cell type. For each variable, the $F$ statistic values for mouse line and cell type were, respectively, as follows: resting membrane potential $(\mathrm{RMP}): F_{(1,25)}=1.62,2.18 ; \tau_{\mathrm{m}}: F_{(1,25)}=0.13,16.2 ; R_{\text {in }}$ : $F_{(1,25)}=0.26,35.9 ;$ I threshold: $F_{(1,25)}=0.0006,17.8$; AP threshold: $F_{(1,25)}=0.57,0.129 ;$ first AP delay: $F_{(1,23)}=13.1,42.9 ;$ AP half-width: $F_{(1,25)}=0.0015,3.39 ;$ AHP amplitude: $F_{(1,23)}=$ $0.63,10.8 ;|I|$ ratio: $F_{(1,25)}=0.12,37.8 ; f-I$ slope: $F_{(1,24)}=0.74,0.74$. Q-Q plot and Shapiro-Wilk analysis revealed a deviation from normality of $|S|$ ratio and $f-I$ slope, for which the ANOVA was performed after log transformation (Shapiro-Wilk: ISI ratio, $p=0.094 ; f-$ slope, $p=0.372$ ).

$\mathrm{P}>30$, which estimate the parameter $y 0$ of the exponential curve fits, did not differ between the $\mathrm{PV}^{+}$neuron subtypes (Fig. 8). Moreover, the P12 values, which estimate the parameter $A$, did not differ between L1/2 BCs and L1/2 ChCs (Fig. 8). Thus, the maturation of $\mathrm{FS}$ properties in L1/2 BCs versus L1/2 ChCs may be distinguished mainly by the rate of development, $\tau_{\mathrm{dev}}$, which for each variable had consistently larger values in $\mathrm{L} 1 / 2 \mathrm{ChCs}$ (Fig. 10), suggesting a slower rate of maturation compared with L1/2 BCs. We next tested the significance of the differences in $\tau_{\mathrm{dev}}$, using the combined curve fit statistical model employed to compare the sEPSC frequency in BCs of different layers. We found that the difference in $\tau_{\mathrm{dev}}$ between L1/2 BCs and L1/2 ChCs was significant in the individual tests for AP half-width $\left(t_{(110)}=\right.$ $1.9151, p=0.029)$ and $f-I$ slope $\left(t_{(97)}=1.498, p=0.037\right)$, but not for the other two parameters (AP-threshold, $t_{(109)}=0.7663, p=$ $\left.0.223 ; \tau_{\mathrm{m}}, t_{(105)}=0.9556, p=0.153\right)$. Given that the four $\tau_{\mathrm{dev}}$ constants were consistently longer in $\mathrm{L} 1 / 2 \mathrm{ChCs}$, we applied a global test using Fisher's method to combine $p$ values (Fisher, 1950; Won et al., 2009), to pool the information from the four comparisons. This approach produced an overall $p$ value of 0.020 , assuming independence of the four individual tests, and a $p$ value of 0.040 , after using Brown's method to estimate correlations between individual tests (see Materials and Methods). Moreover, assuming an average correlation among tests of 0.5 , which is considered very high for tests of different variables, the resulting conservative combined $p$ value is 0.07 . Thus, the global comparison of $\tau_{\mathrm{dev}}$ for the four parameters suggested that FS properties have slower maturation rate in L1/2 ChCs than in L1/2 BCs.

To investigate the development of FS properties in L3/5 BCs, we measured the same 10 variables assessed in $\mathrm{PV}^{+}$neurons from the L1/2 border. At P12, the L3/5 BCs displayed an underdeveloped FS phenotype, similar to that of immature L1/2 BCs, as also reported for layers 3-5 $\mathrm{PV}^{+}$neurons of immature somatosensory cortex (Goldberg et al., 2008, 2011). Comparing the properties of $\mathrm{L} 3 / 5 \mathrm{BCs}$ between $\mathrm{P} 12$ and $\mathrm{P}>28$ revealed that most parameters changed significantly with age, following the same trend observed in L1/2 BCs (Fig. 11). Because we recorded from some mature L3/5 BCs in slices of $\mathrm{Pvalb}^{\mathrm{Cre}}$; Ail4 mice, we compared their electrophysiological properties with those of L3/5 BCs from G42 mice. As observed for $\mathrm{L} 1 / 2$ border $\mathrm{PV}^{+}$neurons, most electro- 


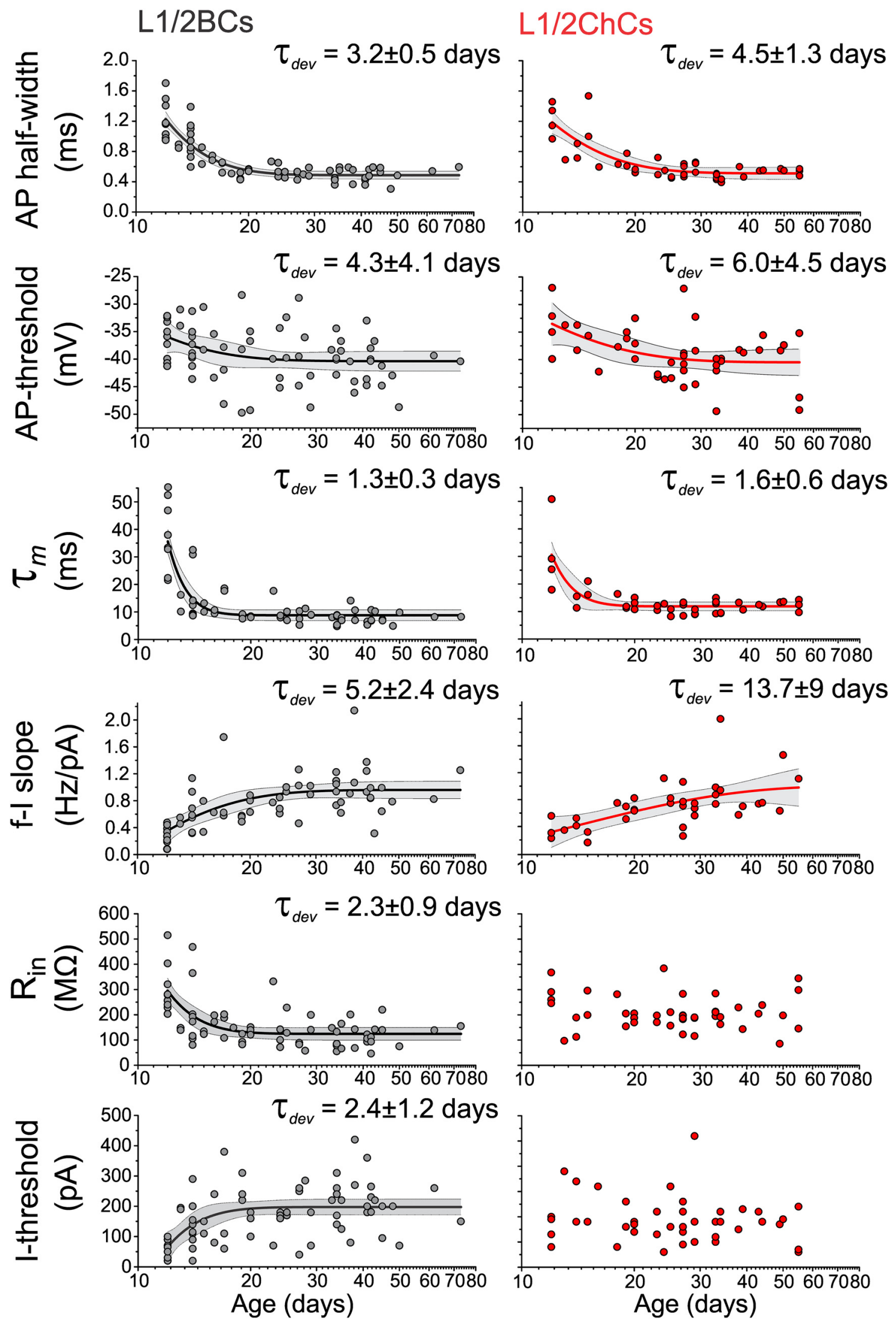

Figure 10. Developmental trajectory of the intrinsic membrane properties contributing to the FS phenotype of $L 1 / 2 \mathrm{BCS}$ and $\mathrm{L} 1 / 2 \mathrm{ChC}$. Shown are plots of the values of each parameter as a function of postnatal age. Each data point represents a single $\mathrm{PV}^{+}$neuron. The plots for four of the parameters, AP half-width, AP threshold, $\tau_{\mathrm{m}}$, and $f-/$ slope, were well fit by an exponential function (thick line) in both the $\mathrm{L} 1 / 2 \mathrm{BC}$ and L1/2 ChC plots. For $R_{\text {in }}$ in $\mathrm{L} 1 / 2 \mathrm{ChCs}$, the exponential curve fit did not converge (see Materials and Methods, Statistical analysis), whereas / threshold did not show a significant effect of age in $\mathrm{L} 1 / 2 \mathrm{ChCs}$ (Fig. 8). In addition to the fitted curves, the $95 \%$ confidence bands of the curve fits are shown, along with the time constants of the single exponential $\tau_{\text {dev }}$ ( \pm SE from the nonlinear regressions). 

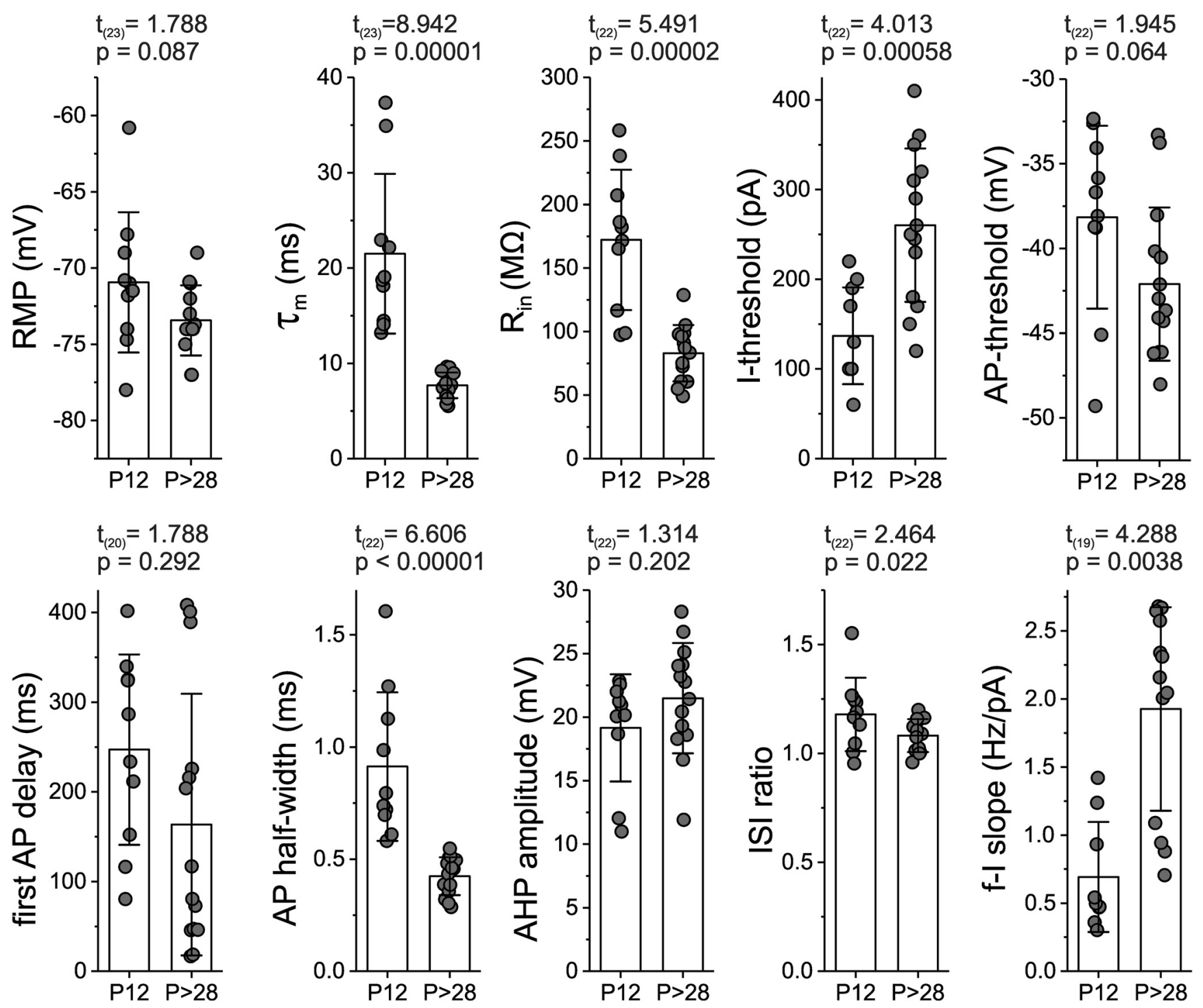

Figure 11. Developmental changes in the intrinsic membrane properties of $L 3 / 5 \mathrm{BC}$. The graphs summarize (mean \pm SD) the data of 10 electrophysiological variables contributing to the FS phenotype of $\mathrm{L} 3 / 5 \mathrm{BC}$, measured from a sample of $\mathrm{PV}{ }^{+}$neurons from $\mathrm{P} 12$ and $\mathrm{P}>28 \mathrm{G} 42$ mice, when all variables reach age-related plateau. Shown above each graph are the $t$ statistics and $p$ values from Student's $t$ tests for each variable. Q-Q plots and Shapiro-Wilk analyses revealed a deviation from normality for AP half-width and ISI ratio, for which the $t$ tests were performed after log transformation (Shapiro-Wilk AP half-width $p=0.560$; ISI ratio $p=0.131$ ).

physiological variables assessed in mature L3/5 BCs (7 of 10) did not differ significantly between mouse lines (Fig. 12). While our data seem to reveal general physiological properties of $\mathrm{PV}^{+}$neurons of all cortical layers independent of specific mouse lines, we cannot rule out the possibility that some $\mathrm{PV}^{+}$neuron subtypes are not labeled in G42 or Pvalb ${ }^{C r e}$;Ai14 mice. Moreover, additional studies are necessary to determine whether the time course of $\mathrm{PV}^{+}$neuron maturation described here only in G42 mice is a general feature of $\mathrm{PV}^{+}$neurons and thus similarly observed in other mouse lines.

To assess the developmental trajectories of FS properties in L3/5 BCs, we applied exponential curve fitting for the five electrophysiological variables that changed significantly with age, and were fit by single exponential functions in both L1/2 and L3/5 BCs. As in L1/2 BCs, the curve fits showed a rapid time course of development, and for AP half-width, $R_{\text {in }}, I$ threshold, and $f-I$ slope, the exponential $\tau_{\text {dev }}$ constants had shorter values in L3/5 BCs (Fig. 13), compared with L1/2 BCs (Fig. 10). However, for $\tau_{\mathrm{m}}$, the value of $\tau_{\mathrm{dev}}$ was greater in L3/5 BCs than in L1/2 BCs.
Moreover, in all cases the differences in $\tau_{\mathrm{dev}}$ between L3/5 and L1/2 BCs were small, and the SEs for $\tau_{\mathrm{dev}}$, from the nonlinear regressions, were relatively large. Therefore, to assess whether FS properties have different maturation rates in $\mathrm{L} 1 / 2 \mathrm{BCs}$ than in L3/5 BCs, we tested the significance of the differences in $\tau_{\text {dev }}$, using combined curve fitting. Importantly, for all variables, except $f-I$ slope, the values at $\mathrm{P} \geq 30$, which estimate $y 0$, did not differ between L1/2 and L3/5 BCs $(p=0.307, p=0.073, p=$ $0.067, p=0.859)$, whereas the values at P12, which estimate $A$, differed significantly ( $p=0.00153, p=0.000023, p=0.0099$, $p=0.000067)$, and were consistently closer to the mature values for each variable in L3/5 BCs. The individual contrasts showed that the $\tau_{\mathrm{dev}}$ values did not differ significantly for any of the five variables (AP half-width, $t_{(130)}=1.838, p=0.0683 ; R_{\mathrm{in}}, t_{(126)}=$ $0.516, p=0.6067 ;$ I threshold, $t_{(129)}=0.384, p=0.7018 ; \tau_{\mathrm{m}}, t_{(124)}=$ $1.1256, p=0.2625 ; f-I$ slope, $\left.t_{(117)}=0.0498, p=0.9603\right)$, suggesting that in L1/2 and L3/5 BCs, FS properties mature at similar exponential rates. In addition, because it is likely that developmental changes in FS properties start before P12, we conclude that the differences in 

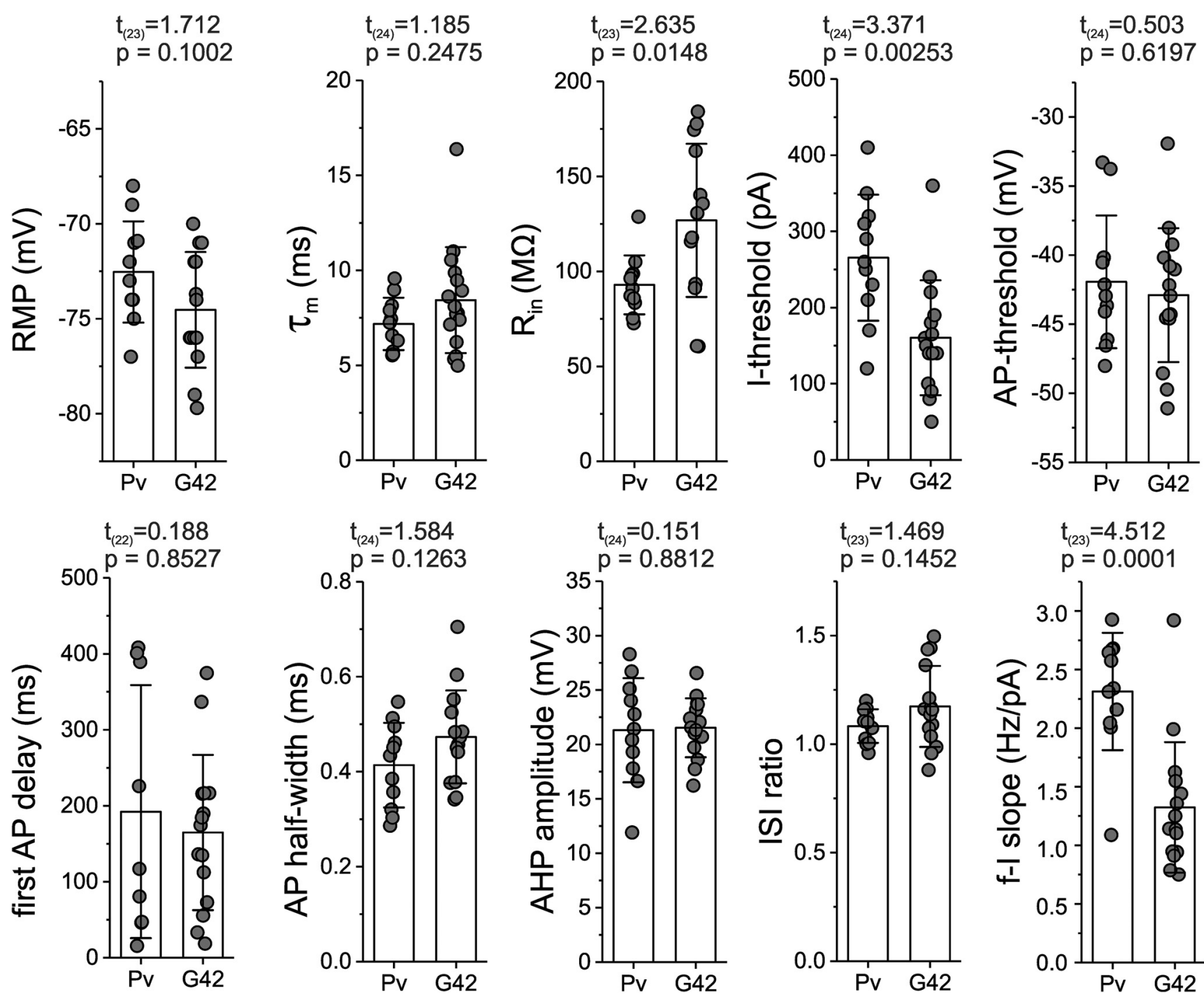

Figure 12. Intrinsic membrane properties of mature L3/5 BCS from G42 versus Pvalb ${ }^{\text {(re }}$;Ai14 mice (Pv). The graphs summarize (mean \pm SD) the data of 10 electrophysiological variables contributing to the $\mathrm{FS}$ phenotype of $\mathrm{L} 3 / 5 \mathrm{BC}$, measured from a sample of $\mathrm{PV}^{+}$neurons from Pvalb ${ }^{\mathrm{Cre}} ; A$ Ai14 mice (P35-P37), and compared with a subset of the GFP ${ }^{+} \mathrm{PV}{ }^{+}$neurons matched by age (P38-P45). Shown above each graph are the $t$ statistics and $p$ values from Student's $t$ tests for each variable. $Q-Q$ plots and Shapiro-Wilk analyses revealed a deviation from normality of first AP delay and $\tau_{\mathrm{m}^{\prime}}$ for which the $t$ tests were performed after $\log$ transformation (Shapiro-Wilk first AP delay $p=0.125 ; \tau_{\mathrm{m}} p=0.723$ ).

P12 values are consistent with an earlier onset of maturation of FS properties in L3/5 BCs than in L1/2 BCs.

\section{Discussion}

The distribution of $\mathrm{PV}^{+} \mathrm{BCs}$ and $\mathrm{ChCs}$ across cortical layers differs beginning early in postnatal development

In two mouse lines with $\mathrm{PV}^{+}$neurons labeled via different genetic mechanisms, the laminar distribution of BCs in PFC is consistent with the presence of $\mathrm{PV}^{+}$neuron somata throughout layers 2-6 (Gabbott et al., 1997; Chattopadhyaya et al., 2004; Rymar and Sadikot, 2007; Bartolini et al., 2013). In contrast, $\mathrm{PV}^{+}$ ChC somata were exclusively positioned near the L1/2 border, in agreement with our previous report that all FS neurons in PFC layer 5 of C57BL/6 mice were BCs (Rotaru et al., 2011). Moreover, in Sprague Dawley rats, $\mathrm{PV}^{+}$BCs are found across PFC layers $2-5$, but $\mathrm{PV}^{+} \mathrm{ChC}$ somata are found only near the $\mathrm{L} 1 / 2$ border (Massi et al., 2012).

Previous work showed that embryonic recombination in Nkx2.1 $1^{\text {CreER }}$ mice labeled numerous ChCs in layer 5 (Taniguchi et al., 2013), which, however, were mostly $\mathrm{PV}^{-}$(Taniguchi et al.,
2013), and thus may represent a subpopulation not studied here. It appears, therefore, that two ChC subpopulations, $\mathrm{PV}^{+}$and $\mathrm{PV}^{-} \mathrm{ChCs}$, are found in the cortex, but $\mathrm{PV}^{+} \mathrm{ChCs}$ are present only near the L1/2 border. Additional work is necessary to determine whether deep-layer ChCs represent a $\mathrm{PV}^{-}$subtype or contain very low PV levels, undetectable with current methods. Since PV expression is activity-dependent (Patz et al., 2004), and we found that $\mathrm{L} 1 / 2 \mathrm{ChCs}$ have low excitatory drive, it is possible that $\mathrm{ChCs}$ are less active than $\mathrm{BCs}$, and therefore express lower PV levels. Indeed, in rat PFCs, ChCs have weaker PV immunoreactivity compared with BCs (Massi et al., 2012). Independent of the mechanisms that determine PV levels in ChCs, we found that the low abundance of $\mathrm{PV}^{+} \mathrm{ChCs}$ in deep layers of PFCs is observed as early as P12.

ChCs and BCs have rapid and cell-type-dependent trajectories of physiological maturation

We found that during development after P12, glutamate synapse strength, as revealed by the peak sEPSC AMPAR $_{\text {amplitude, does }}$ not change with age in $\mathrm{PFC} \mathrm{PV}^{+}$neurons. In contrast, the 

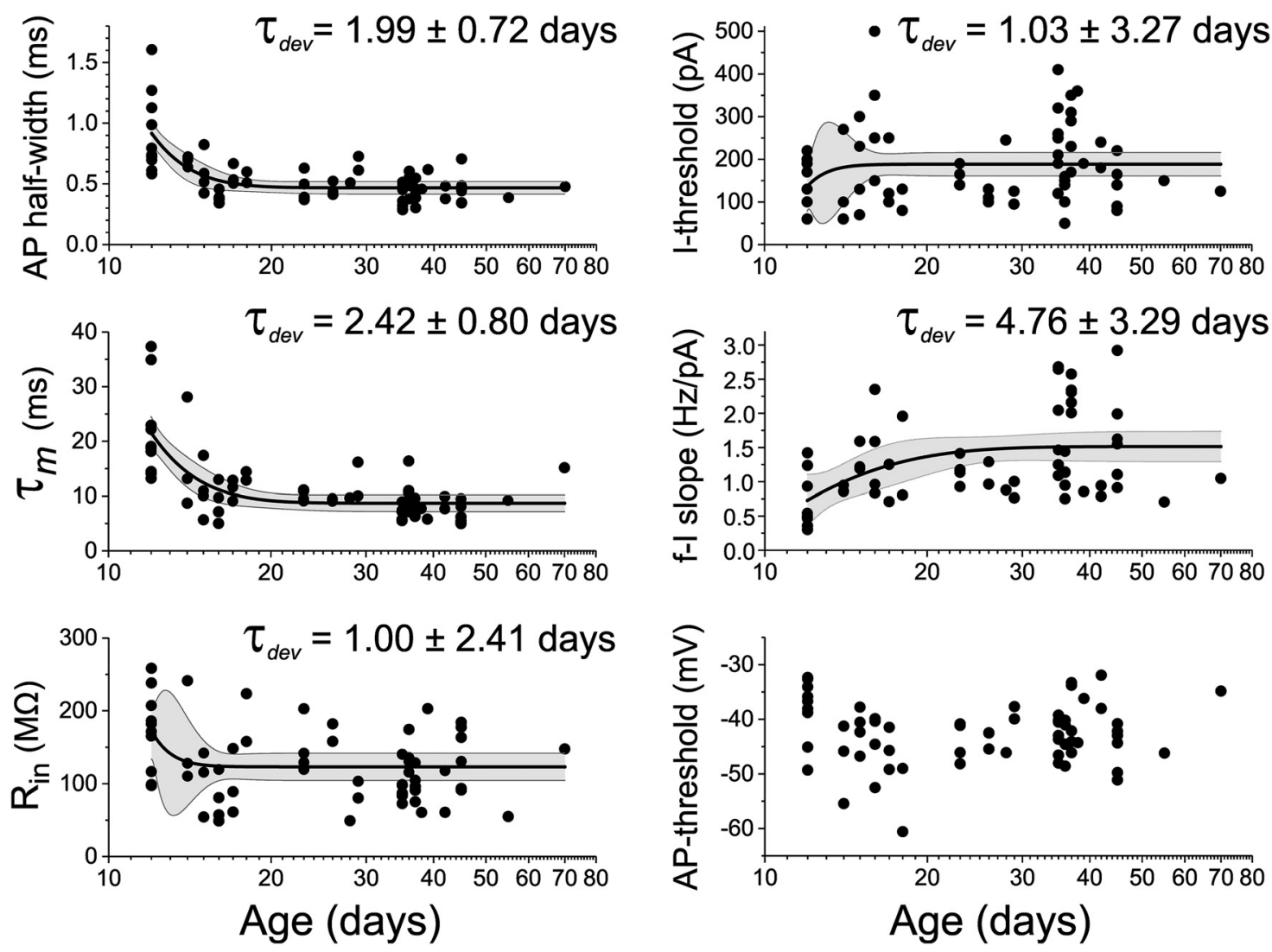

Figure 13. Developmental trajectory of intrinsic electrophysiology variables in L3/5 BCS. Shown are plots of the values of each parameter as a function of postnatal age. Each data point represents a single $\mathrm{PV}^{+}$neuron. Four of the plots (AP duration, $R_{\mathrm{in}}, \tau_{\mathrm{m}}$, and / threshold) were well fit by an exponential function (thick line). For the AP threshold there was no significant age effect (Fig. 11). In addition to the fitted curves, $95 \%$ confidence bands of the curve fits are shown, as well as the exponential constant values $\tau_{d e v}$ ( \pm SEs from the nonlinear regressions).

sEPSC ${ }_{\text {AMPAR }}$ frequency increased significantly with age in BCs, markedly enhancing the excitatory drive, but did not change in ChCs. Our data also suggest that the increase in sEPSC $_{\mathrm{AMPAR}}$ frequency is not related to a developmental increase in network activity, as assessed in acute slices, or in glutamate release probability. Consistent with the idea that the higher EPSC frequency reflects increasing numbers of excitatory synapses in BCs, the density of VGlut1-containing puncta, in apposition to $\mathrm{PV}^{+}$neuron somata in PFC layers 5-6, increases significantly between P14 and P40 (Yang et al., 2013). Since deeper-layer $\mathrm{PV}^{+}$neurons migrate and populate their target layer earlier (Rymar and Sadikot, 2007), it is possible that an earlier laminar positioning determines an earlier trajectory of excitatory synaptogenesis in $\mathrm{L} 3 / 5$ versus $\mathrm{L} 1 / 2$ BCs, consistent with the higher sEPSC $_{\mathrm{AMPA}}$ frequency observed here in P12 L3/5 BCs. Similarly, the later migration and laminar positioning of ChCs compared with BCs suggested by previous work (Inan et al., 2012; Taniguchi et al., 2013) may underlie a different trajectory of synaptogenesis in ChCs.

Because the maturation of FS properties is thought to be activity-dependent, the marked differences in excitatory input development would suggest that in ChCs, which have lower excitatory drive throughout development, the FS phenotype has a slower maturation rate. Moreover, our data suggest that an earlier maturation of excitatory inputs in L3/5 BCs may correlate with an earlier maturation of FS properties in L3/5 BCs than in L1/2 BCs. Although we did not test a causal relation between maturation of excitatory inputs and FS properties, we assessed the developmental trajectories of multiple electrophysiological properties contributing to the FS phenotype. We found that several of these properties changed with age following trajectories that were well fit by exponential functions indicating that FS properties mature at faster rate in L1/2 BCs than in L1/2 ChCs. In contrast, the FS phenotype matured at similar rates in $\mathrm{L} 3 / 5$ and $\mathrm{L} 1 / 2 \mathrm{BCs}$, but possibly with an earlier onset in L3/5 BCs.

Estimates from the exponential curve fits showed that by $\sim$ P21 FS properties were at $96.1-99.9 \%$ of plateau in L3/5 BCs, 88.6-99.6\% in L1/2 BCs, and 66.5-96.2\% in L1/2 ChCs, suggesting that at P21, near the onset of puberty (Nelson et al., 1990; Laviola et al., 2003), $\mathrm{PV}^{+}$neurons reached a mature state. Thus, despite the differences in developmental trajectories revealed by our study, all $\mathrm{PV}^{+}$neurons across PFC layers $2-5$ exhibit physiological properties of an advanced maturation state by the onset of puberty.

The $\mathrm{PV}^{+}$neuron maturation trajectory has implications for the development of PFC circuit function and the pathogenesis of schizophrenia

Although we did not perform tests of a causal relation between the development of excitatory inputs and FS properties, our results are consistent with the idea that excitatory drive from glutamate synapses shapes the maturation of the FS phenotype. The age-related changes in the membrane properties of $\mathrm{BCs}$ and ChCs reported here are consistent with previous work showing that $\mathrm{PV}^{+}$neuron maturation enables fast physiological signaling (Doischer et al., 2008; Goldberg et al., 2011). These 
include a decrease in $R_{\mathrm{in}}$ and shortening of $\tau_{\mathrm{m}}$, which contribute to the short summation time window, and fast dendrosomatic propagation, of synaptic potentials (Goldberg et al., 2011). AP firing similarly developed faster signaling mode, since spikes turned briefer, and low spike-frequency adaptation emerged after P12. Some of these changes were previously attributed to changes in potassium channel gene expression (Okaty et al., 2009), including the Kv3, Kir2, and TASK/TWIK subfamilies of two-pore domain weakly rectifying $\mathrm{K}^{+}$channels (Goldberg et al., 2011).

BCs developed properties consistent with the FS phenotype crucial for their role in cortical circuits (Buzsáki and Wang, 2012; $\mathrm{Hu}$ et al., 2014). However, mature ChCs differed from BCs in some features, confirming previous reports (Woodruff et al., 2009; Povysheva et al., 2013; Taniguchi et al., 2013). Particularly, ChCs had higher $R_{\mathrm{in}}$, longer $\tau_{\mathrm{m}}$, and greater spike-frequency adaptation, suggesting that $\mathrm{ChC}$ physiology somewhat differs from the classical FS properties thought to be necessary to produce gamma band synchrony (Pike et al., 2000; Bartos et al., 2007; Hu et al., 2011). Indeed, unlike BCs, ChCs may not contribute rhythmic inhibition during gamma oscillations (Gulyás et al., 2010; Dugladze et al., 2012; Massi et al., 2012).

Our data suggest that the FS phenotype matures later in $\mathrm{PV}^{+}$cells of superficial layers, where corticocortical projection pyramidal cells are more abundant (DeFelipe and Fariñas, 1992). Thus, $\mathrm{PV}^{+}$neuron-dependent control may mature later for corticocortical than corticosubcortical output, conveyed via deep-layer pyramidal cells. Our data also indicate that excitatory inputs and intrinsic physiology have mature features in all $\mathrm{PFC} \mathrm{PV}{ }^{+}$neurons at or before the onset of puberty. Hence, $\mathrm{PV}^{+}$neuron maturation may not contribute directly to the improvement of PFC-dependent cognition during adolescence and early adult life. However, we did not study the GABA synapses by which $\mathrm{PV}^{+}$neurons control pyramidal cell activity. These synapses could show a protracted development into adolescence and young adulthood.

Our results may have implications for understanding how $\mathrm{PV}^{+}$neurons are altered in schizophrenia. First, our data suggest that the deficit of excitatory synapses in $\mathrm{PV}^{+}$neurons in schizophrenia (Chung et al., 2016), if produced during development, may disrupt the FS phenotype. Indeed, voltage-dependent potassium channels normally expressed by $\mathrm{PV}^{+}$neurons (Rudy and McBain, 2001; Okaty et al., 2009; Georgiev et al., 2012) show altered expression in schizophrenia (Georgiev et al., 2014; Yanagi et al., 2014). Second, our data indicate that BCs may be particularly susceptible to the effects of schizophrenia risk factors before puberty, when excitatory drive increases markedly. Indeed, ablation of the NMDA receptor subunit GluN1, starting at $\sim \mathrm{P} 7$, affects $\mathrm{PV}^{+}$cell function, producing schizophrenia-like behavioral disturbances in adulthood (Belforte et al., 2010). Conversely, GluN1 deletion starting by $\sim \mathrm{P} 60$, when $\mathrm{PV}^{+}$cells are physiologically mature, does not produce significant effects (Belforte et al., 2010). Interestingly, $\mathrm{PV}^{+}$cells develop normally in the PFC of Dlx5/6-deficient mice until $\sim$ P50, but then show altered physiology, correlating with cognitive deficits, by $\sim$ P63P80 (Cho et al., 2015). Similarly, in ErbB4-deficient mice, excitatory synapses on PFC $\mathrm{PV}^{+}$cells develop normally until P20 (Yang et al., 2013), but show alterations at $\mathrm{P} \geq 40$ (Ting et al., 2011; Yang et al., 2013). Thus, $\mathrm{PV}^{+}$neurons may be sensitive to the disruptive effects of schizophrenia risk alleles and environmental risk factors, not only during prepubertal development, but also during later periods, when they display adult-like physiology.

\section{References}

Bartolini G, Ciceri G, Marín O (2013) Integration of GABAergic interneurons into cortical cell assemblies: lessons from embryos and adults. Neuron 79:849-864. CrossRef Medline

Bartos M, Vida I, Jonas P (2007) Synaptic mechanisms of synchronized gamma oscillations in inhibitory interneuron networks. Nat Rev Neurosci 8:45-56. CrossRef Medline

Bates DM, Chambers JM (1992) Nonlinear models. In: Statistical models in S (Chambers JM, Hastie TJ, eds). Pacific Grove, CA: Wadsworth and Brooks/Cole.

Bates DM, Watts DG (1988) Nonlinear Regression Analysis and Its Applications. Hoboken, NJ: Wiley.

Belforte JE, Zsiros V, Sklar ER, Jiang Z, Yu G, Li Y, Quinlan EM, Nakazawa K (2010) Postnatal NMDA receptor ablation in corticolimbic interneurons confers schizophrenia-like phenotypes. Nat Neurosci 13:76-83. CrossRef Medline

Brown M (1975) A method for combining non-independent, one-sided tests of significance. Biometrics 31:987-992. CrossRef

Buchanan KA, Blackman AV, Moreau AW, Elgar D, Costa RP, Lalanne T, Tudor Jones AA, Oyrer J, Sjöström PJ (2012) Target-specific expression of presynaptic NMDA receptors in neocortical microcircuits. Neuron 75:451-466. CrossRef Medline

Buzsáki G, Wang XJ (2012) Mechanisms of gamma oscillations. Annu Rev Neurosci 35:203-225. CrossRef Medline

Carlén M, Meletis K, Siegle JH, Cardin JA, Futai K, Vierling-Claassen D, Rühlmann C, Jones SR, Deisseroth K, Sheng M, Moore CI, Tsai LH (2012) A critical role for NMDA receptors in parvalbumin interneurons for gamma rhythm induction and behavior. Mol Psychiatry 17:537-548. CrossRef Medline

Chattopadhyaya B, Di Cristo G, Higashiyama H, Knott GW, Kuhlman SJ, Welker E, Huang ZJ (2004) Experience and activity-dependent maturation of perisomatic GABAergic innervation in primary visual cortex during a postnatal critical period. J Neurosci 24:9598-9611. CrossRef Medline

Cho KK, Hoch R, Lee AT, Patel T, Rubenstein JL, Sohal VS (2015) Gamma rhythms link prefrontal interneuron dysfunction with cognitive inflexibility in Dlx5/6(+/-) mice. Neuron 85:1332-1343. CrossRef Medline

Chung DW, Fish KN, Lewis DA (2016) Pathological basis for deficient excitatory drive to cortical parvalbumin interneurons in schizophrenia. Am J Psychiatry 173:1131-1139. CrossRef Medline

DeFelipe J, Fariñas I (1992) The pyramidal neuron of the cerebral cortex: morphological and chemical characteristics of the synaptic inputs. Prog Neurobiol 39:563-607. CrossRef Medline

DeFelipe J, López-Cruz PL, Benavides-Piccione R, Bielza C, Larrañaga P, Anderson S, Burkhalter A, Cauli B, Fairén A, Feldmeyer D, Fishell G, Fitzpatrick D, Freund TF, González-Burgos G, Hestrin S, Hill S, Hof PR, Huang J, Jones EG, Kawaguchi Y. et al. (2013) New insights into the classification and nomenclature of cortical GABAergic interneurons. Nat Rev Neurosci 14:202-216. CrossRef Medline

Dehorter N, Ciceri G, Bartolini G, Lim L, del Pino I, Marín O (2015) Tuning of fast-spiking interneuron properties by an activity-dependent transcriptional switch. Science 349:1216-1220. CrossRef Medline

Del Río JA, de Lecea L, Ferrer I, Soriano E (1994) The development of parvalbumin-immunoreactivity in the neocortex of the mouse. Brain Res Dev Brain Res 81:247-259. CrossRef Medline

Doischer D, Hosp JA, Yanagawa Y, Obata K, Jonas P, Vida I, Bartos M (2008) Postnatal differentiation of basket cells from slow to fast signaling devices. J Neurosci 28:12956-12968. CrossRef Medline

Dugladze T, Schmitz D, Whittington MA, Vida I, Gloveli T (2012) Segregation of axonal and somatic activity during fast network oscillations. Science 336:1458-1461. CrossRef Medline

Fisher RA (1950) Statistical methods for research workers. Edinburgh: Oliver and Boyd.

Gabbott PL, Dickie BG, Vaid RR, Headlam AJ, Bacon SJ (1997) Localcircuit neurones in the medial prefrontal cortex (areas 25, 32, and 24b) in the rat: morphology and quantitative distribution. J Comp Neurol 377: 465-499. CrossRef Medline

Georgiev D, González-Burgos G, Kikuchi M, Minabe Y, Lewis DA, 
Hashimoto T (2012) Selective expression of KCNS3 potassium channel alpha-subunit in parvalbumin-containing GABA neurons in the human prefrontal cortex. PLoS One 7:e43904. CrossRef Medline

Georgiev D, Arion D, Enwright JF, Kikuchi M, Minabe Y, Corradi JP, Lewis DA, Hashimoto T (2014) Lower gene expression for KCNS3 potassium channel subunit in parvalbumin-containing neurons in the prefrontal cortex in schizophrenia. Am J Psychiatry 171:62-71. CrossRef Medline

Goldberg EM, Clark BD, Zagha E, Nahmani M, Erisir A, Rudy B (2008) K+ channels at the axon initial segment dampen near-threshold excitability of neocortical fast-spiking GABAergic interneurons. Neuron 58:387-400. CrossRef Medline

Goldberg EM, Jeong HY, Kruglikov I, Tremblay R, Lazarenko RM, Rudy B (2011) Rapid developmental maturation of neocortical FS cell intrinsic excitability. Cereb Cortex 21:666-682. CrossRef Medline

Gonzalez-Burgos G, Cho RY, Lewis DA (2015) Alterations in cortical network oscillations and parvalbumin neurons in schizophrenia. Biol Psychiatry 77:1031-1040. CrossRef Medline

Gulyás AI, Szabó GG, Ulbert I, Holderith N, Monyer H, Erdélyi F, Szabó G, Freund TF, Hájos N (2010) Parvalbumin-containing fast-spiking basket cells generate the field potential oscillations induced by cholinergic receptor activation in the hippocampus. J Neurosci 30:15134-15145. CrossRef Medline

Henze DA, González-Burgos GR, Urban NN, Lewis DA, Barrionuevo G (2000) Dopamine increases excitability of pyramidal neurons in primate prefrontal cortex. J Neurophysiol 84:2799-2809. Medline

Hu H, Ma Y, Agmon A (2011) Submillisecond firing synchrony between different subtypes of cortical interneurons connected chemically but not electrically. J Neurosci 31:3351-3361. CrossRef Medline

Hu H, Gan J, Jonas P (2014) Interneurons. Fast-spiking, parvalbumin(+) GABAergic interneurons: from cellular design to microcircuit function. Science 345:1255263. CrossRef Medline

Huang ZJ, Kirkwood A, Pizzorusso T, Porciatti V, Morales B, Bear MF, Maffei L, Tonegawa S (1999) BDNF regulates the maturation of inhibition and the critical period of plasticity in mouse visual cortex. Cell 98:739-755. CrossRef Medline

Inan M, Welagen J, Anderson SA (2012) Spatial and temporal bias in the mitotic origins of somatostatin- and parvalbumin-expressing interneuron subgroups and the chandelier subtype in the medial ganglionic eminence. Cereb Cortex 22:820-827. CrossRef Medline

Inan M, Blázquez-Llorca L, Merchán-PérezA, Anderson SA, DeFelipe J, Yuste $R$ (2013) Dense and overlapping innervation of pyramidal neurons by chandelier cells. J Neurosci 33:1907-1914. CrossRef Medline

Kim H, Ährlund-Richter S, Wang X, Deisseroth K, Carlén M (2016) Prefrontal parvalbumin neurons in control of attention. Cell 164:208-218. CrossRef Medline

Klausberger T, Somogyi P (2008) Neuronal diversity and temporal dynamics: the unity of hippocampal circuit operations. Science 321:53-57. CrossRef Medline

Koester HJ, Johnston D (2005) Target cell-dependent normalization of transmitter release at neocortical synapses. Science 308:863-866. CrossRef Medline

Kole MH, Stuart GJ (2012) Signal processing in the axon initial segment. Neuron 73:235-247. CrossRef Medline

Lagler M, Tugrul Ozdemir AT, Lagoun S, Malagon-Vina H, Borhegyi Z, Hauer R, Jelem A, Klausberger T (2016) Divisions of identified parvalbuminexpressing basket cells during working memory-guided decision making. Neuron 91:1390-1401. CrossRef Medline

Langdon RB, Johnson JW, Barrionuevo G (1995) Posttetanic potentiation and presynaptically induced long-term potentiation at the mossy fiber synapse in rat hippocampus. J Neurobiol 26:370-385. CrossRef Medline

Laviola G, Macrì S, Morley-Fletcher S, Adriani W (2003) Risk-taking behavior in adolescent mice: psychobiological determinants and early epigenetic influence. Neurosci Biobehav Rev 27:19-31. CrossRef Medline

Lu J, Tucciarone J, Lin Y, Huang ZJ (2014) Input-specific maturation of synaptic dynamics of parvalbumin interneurons in primary visual cortex. Proc Natl Acad Sci U S A 111:16895-16900. CrossRef Medline

Luna B, Marek S, Larsen B, Tervo-Clemmens B, Chahal R (2015) An integrative model of the maturation of cognitive control. Annu Rev Neurosci 38:151-170. CrossRef Medline

Massi L, Lagler M, Hartwich K, Borhegyi Z, Somogyi P, Klausberger T (2012) Temporal dynamics of parvalbumin-expressing axo-axonic and basket cells in the rat medial prefrontal cortex in vivo. J Neurosci 32:1649616502. CrossRef Medline

Miao Q, Yao L, Rasch MJ, Ye Q, Li X, Zhang X (2016) Selective maturation of temporal dynamics of intracortical excitatory transmission at the critical period onset. Cell Rep 16:1677-1689. CrossRef Medline

Miller MN, Okaty BW, Kato S, Nelson SB (2011) Activity-dependent changes in the firing properties of neocortical fast-spiking interneurons in the absence of large changes in gene expression. Dev Neurobiol 71:62-70. CrossRef Medline

Moskvina V, O’Dushlaine C, Purcell S, Craddock N, Holmans P, O’Donovan MC (2011) Evaluation of an approximation method for assessment of overall significance of multiple-dependent tests in a genomewide association study. Genet Epidemiol 35:861-866. CrossRef Medline

Nelson JF, Karelus K, Felicio LS, Johnson TE (1990) Genetic influences on the timing of puberty in mice. Biol Reprod 42:649-655. CrossRef Medline

Okaty BW, Nelson SB (2013) The maturation of firing properties of forebrain GABAergic neurons. In: Comprehensive developmental neuroscience: cellular migration and formation of neuronal connections, first edition (Rubenstein JL, Rakic P, eds), pp 955-973. San Diego: Academic.

Okaty BW, Miller MN, Sugino K, Hempel CM, Nelson SB (2009) Transcriptional and electrophysiological maturation of neocortical fastspiking GABAergic interneurons. J Neurosci 29:7040-7052. CrossRef Medline

Patz S, Grabert J, Gorba T, Wirth MJ, Wahle P (2004) Parvalbumin expression in visual cortical interneurons depends on neuronal activity and TrkB ligands during an early period of postnatal development. Cereb Cortex 14:342-351. CrossRef Medline

Paxinos G, Franklin KBJ (2001) The mouse brain in stereotaxic coordinates. San Diego: Academic.

Pike FG, Goddard RS, Suckling JM, Ganter P, Kasthuri N, Paulsen O (2000) Distinct frequency preferences of different types of rat hippocampal neurones in response to oscillatory input currents. J Physiol 529:205-213. CrossRef Medline

Povysheva NV, Zaitsev AV, Gonzalez-Burgos G, Lewis DA (2013) Electrophysiological heterogeneity of fast-spiking interneurons: chandelier versus basket cells. PLoS One 8:e70553. CrossRef Medline

Rotaru DC, Yoshino H, Lewis DA, Ermentrout GB, Gonzalez-Burgos G (2011) Glutamate receptor subtypes mediating synaptic activation of prefrontal cortex neurons: relevance for schizophrenia. J Neurosci 31: 142-156. CrossRef Medline

Roux L, Buzsáki G (2015) Tasks for inhibitory interneurons in intact brain circuits. Neuropharmacology 88:10-23. CrossRef Medline

Rudy B, McBain CJ (2001) Kv3 channels: voltage-gated K+ channels designed for high-frequency repetitive firing. Trends Neurosci 24:517-526. CrossRef Medline

Rymar VV, Sadikot AF (2007) Laminar fate of cortical GABAergic interneurons is dependent on both birthdate and phenotype. J Comp Neurol 501:369-380. CrossRef Medline

Sippy T, Yuste R (2013) Decorrelating action of inhibition in neocortical networks. J Neurosci 33:9813-9830. CrossRef Medline

Sohal VS, Zhang F, Yizhar O, Deisseroth K (2009) Parvalbumin neurons and gamma rhythms enhance cortical circuit performance. Nature 459: 698-702. CrossRef Medline

Somogyi P, Tamás G, Lujan R, Buhl EH (1998) Salient features of synaptic organisation in the cerebral cortex. Brain Res Rev 26:113-135. CrossRef Medline

Soriano E, Del Rio JA, Ferrer I, Auladell C, De Lecea L, Alcantara S (1992) Late appearance of parvalbumin-immunoreactive neurons in the rodent cerebral cortex does not follow an 'inside-out' sequence. Neurosci Lett 142:147-150. CrossRef Medline

Spruston N, Jaffe DB, Johnston D (1994) Dendritic attenuation of synaptic potentials and currents: the role of passive membrane properties. Trends Neurosci 17:161-166. CrossRef Medline

Szabadics J, Varga C, Molnár G, Oláh S, Barzó P, Tamás G (2006) Excitatory effect of GABAergic axo-axonic cells in cortical microcircuits. Science 311:233-235. CrossRef Medline

Tai Y, Janas JA, Wang CL, Van Aelst L (2014) Regulation of chandelier cell cartridge and bouton development via DOCK7-mediated ErbB4 activation. Cell Rep 6:254-263. CrossRef Medline

Taniguchi H, Lu J, Huang ZJ (2013) The spatial and temporal origin of 
chandelier cells in mouse neocortex. Science 339:70-74. CrossRef Medline

Ting AK, Chen Y, Wen L, Yin DM, Shen C, Tao Y, Liu X, Xiong WC, Mei L (2011) Neuregulin 1 promotes excitatory synapse development and function in GABAergic interneurons. J Neurosci 31:15-25. CrossRef Medline

Won S, Morris N, Lu Q, Elston RC (2009) Choosing an optimal method to combine P-values. Stat Med 28:1537-1553. CrossRef Medline

Woodruff A, Xu Q, Anderson SA, Yuste R (2009) Depolarizing effect of neocortical chandelier neurons. Front Neural Circuits 3:15. CrossRef Medline

Woodruff AR, McGarry LM, Vogels TP, Inan M, Anderson SA, Yuste R (2011) State-dependent function of neocortical chandelier cells. J Neurosci 31:17872-17886. CrossRef Medline
Yanagi M, Joho RH, Southcott SA, Shukla AA, Ghose S, Tamminga CA (2014) Kv3.1-containing $\mathrm{K}(+)$ channels are reduced in untreated schizophrenia and normalized with antipsychotic drugs. Mol Psychiatry 19:573-579. CrossRef Medline

Yang JM, Zhang J, Chen XJ, Geng HY, Ye M, Spitzer NC, Luo JH, Duan SM, Li XM (2013) Development of GABA circuitry of fast-spiking basket interneurons in the medial prefrontal cortex of erbb4-mutant mice. J Neurosci 33:19724-19733. CrossRef Medline

Zhu Y, Stornetta RL, Zhu JJ (2004) Chandelier cells control excessive cortical excitation: characteristics of whisker-evoked synaptic responses of layer 2/3 nonpyramidal and pyramidal neurons. J Neurosci 24:51015108. CrossRef Medline 